\title{
Persistent luminescence nanoparticles for cancer theranostics application
}

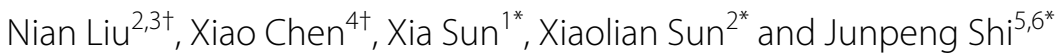

\begin{abstract}
Persistent luminescence nanoparticles (PLNPs) are unique optical materials that emit afterglow luminescence after ceasing excitation. They exhibit unexpected advantages for in vivo optical imaging of tumors, such as autofluorescence-free, high sensitivity, high penetration depth, and multiple excitation sources (UV light, LED, NIR laser, X-ray, and radiopharmaceuticals). Besides, by incorporating other functional molecules, such as photosensitizers, photothermal agents, or therapeutic drugs, PLNPs are also widely used in persistent luminescence (PersL) imaging-guided tumor therapy. In this review, we first summarize the recent developments in the synthesis and surface functionalization of PLNPs, as well as their toxicity studies. We then discuss the in vivo PersL imaging and multimodal imaging from different excitation sources. Furthermore, we highlight PLNPs-based cancer theranostics applications, such as fluorescenceguided surgery, photothermal therapy, photodynamic therapy, drug/gene delivery and combined therapy. Finally, future prospects and challenges of PLNPs in the research of translational medicine are also discussed.
\end{abstract}

Keywords: Persistent luminescence nanoparticles, Synthesis, Surface modification, PersL imaging, Multiple excitation sources, Theranostics

\section{Introduction}

With the increasing number incidence of fatal diseases like cancer, there is a growing need for precise diagnosis and efficient therapy [1]. Therefore, nanomedicines have been proposed to use nanotechnology to endow both imaging and therapeutic capabilities to achieve cancer theranostics [2-6]. Although a range of nanomaterials have been developed for biomedical applications, persistent luminescence nanoparticles (PLNPs) as unique optical materials have attracted extensive attention for

\footnotetext{
*Correspondence: sunxia8446@qq.com; xiaolian_sun@cpu.edu.cn; shijunpeng10@mails.ucas.edu.cn

${ }^{\dagger}$ Nian Liu and Xiao Chen contributed equally to this work

${ }^{1}$ Xiamen Cardiovascular Hospital, Xiamen University, Xiamen 361015 , China

2 State Key Laboratory of Natural Medicines, Key Laboratory of Drug Quality Control and Pharmacovigilance, Department of Pharmaceutical Analysis, China Pharmaceutical University, Nanjing 210009, China ${ }^{5}$ Key Laboratory of Design and Assembly of Functional Nanostructures, Fujian Institute of Research On the Structure of Matter, Chinese Academy of Sciences, Fuzhou 350002, China

Full list of author information is available at the end of the article
}

excitation-free optical imaging and cancer therapy due to persistent luminescence (PersL) property and nanocarrier structures $[7,8]$. PLNPs can store part of the excitation energy and then release the photonic emission for an appreciable time after ceasing excitation. Such continuous luminescence phenomenon is called PersL or afterglow luminescence, which is achieved by forming defects by doping emitter ions in a specific host, and capturing and releasing electrons through these defects $[9,10]$. By tuning the host and emitter, it is possible to obtain PLNPs with different emission wavelengths from UV to nearinfrared (NIR) region [9].

In recent years, PLNPs exhibit outstanding strengths in the field of tumor diagnosis and treatment. Firstly, compared to traditional fluorescent agents (such as semiconductor quantum dots $[11,12]$, upconversion nanoparticles $[13,14]$, organic dyes $[15,16])$, optical imaging with PLNPs can be freed from real-time excitation by external light sources, thus completely avoiding interference of autofluorescence and enabling high-sensitive in vivo imaging. Secondly, PLNPs can be excited by multiple

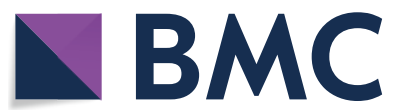

(c) The Author(s) 2021. This article is licensed under a Creative Commons Attribution 4.0 International License, which permits use, sharing, adaptation, distribution and reproduction in any medium or format, as long as you give appropriate credit to the original author(s) and the source, provide a link to the Creative Commons licence, and indicate if changes were made. The images or other third party material in this article are included in the article's Creative Commons licence, unless indicated otherwise in a credit line to the material. If material is not included in the article's Creative Commons licence and your intended use is not permitted by statutory regulation or exceeds the permitted use, you will need to obtain permission directly from the copyright holder. To view a copy of this licence, visit http://creativeco mmons.org/licenses/by/4.0/. The Creative Commons Public Domain Dedication waiver (http://creativecommons.org/publicdomain/ zero/1.0/) applies to the data made available in this article, unless otherwise stated in a credit line to the data. 
excitation sources, such as UV, LED, NIR laser, X-ray, and radiopharmaceuticals, which overcome the poor imaging quality and the poor penetration depth caused by short-wavelength excitation [17]. Thirdly, PLNPs can be easily doped or modified with elements/ligands from other imaging modalities to enable multimodal imaging of live subjects, which provide more sensitive and accurate information for disease diagnostics. Fourth, PLNPs with hollow or mesoporous structures are also suited for drug delivery. Owing to their versatile surface functionality, photothermal agents, chemodrugs, photosensitizers (PSs) or genes can be easily loaded into the PLNPs nanoplatforms for PersL imaging-guided therapy. Inspired by these characteristic advantages of PLNPs, an increasing number of researches have been reported for PLNPsbased bioimaging and therapy. Though some reviews have been shown from different aspects of PLNPs field $[7,9,17-21]$, it is still important to make a new summarization to stress on the cancer theranostics application using the rational designed PLNPs nanoplatforms.

Herein, we primarily summarize the recent progress of biomedical PLNPs from the rational design of PLNPs nanoplatforms to the cancer theranostics application (Fig. 1). Instead of giving a complete historical report of PLNPs, we highlight the newly developed strategies for their synthesis methods, surface functionalization, and biosafety. Subsequently, we discuss the in vivo PersL imaging and multimodal imaging with different excitation sources. Then, we showcase the tumor theranostic applications of PLNPs, including PersL imaging-guided surgery, photothermal therapy (PTT), photodynamic therapy (PDT), chemotherapy, gene

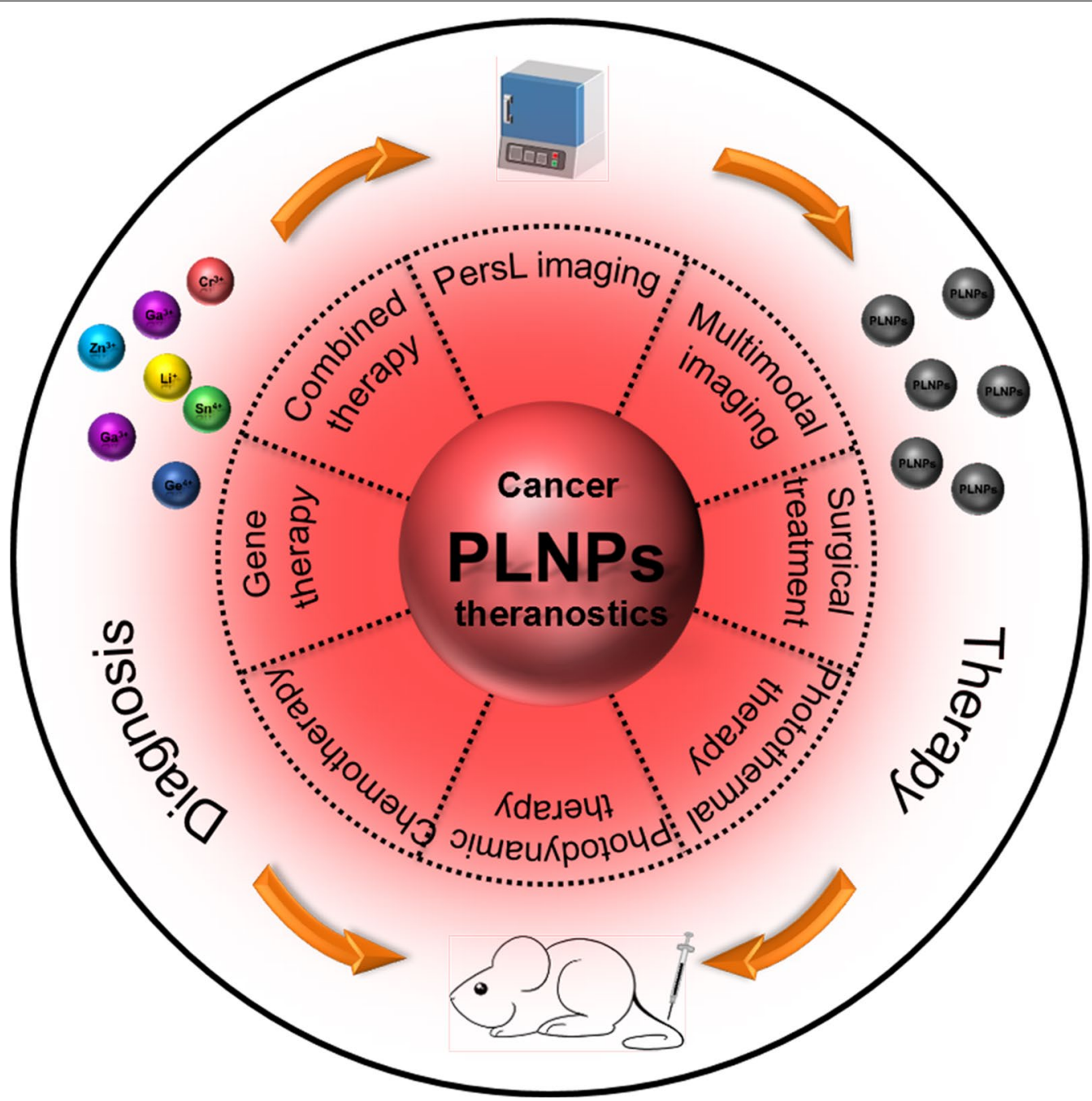

Fig. 1 Graphic illustration of the cancer theranostics application of PLNPS 
therapy, and combined therapy. Finally, we provide the future outlook for PLNPs with the challenging areas.

\section{PLNPs design considerations}

PersL mechanisms

Understanding the PersL mechanism of PLNPs does good for the rational design of PLNPs with long PersL and strong brightness. There are three basic elements in PLNPs: host, emitter, and traps. The host is the main body of PLNPs and acts as the carrier of the emitters. The composition and structure of the host have a certain influence on the spectral structure of the emitter, such as the shape and emission spectrum [9]. The emitters are usually served by rare-earth ions, transition metal ions, or main group elements in PLNPs, such as $\mathrm{Eu}^{2+}, \mathrm{Sm}^{3+}$, $\mathrm{Cr}^{3+}, \mathrm{Mn}^{2+}, \mathrm{Bi}^{3+}$, etc. The luminescent wavelength of PLNPs is mainly determined by their emitters $[10,22]$. The traps are an energy state that can trap electrons in the forbidden band. The traps are usually formed by intrinsic defects or ion doping into the host, which determines the PL time and intensity $[23,24]$.

The mechanism of producing PersL is different under different excitation sources. The widely accepted model of the PersL mechanism is shown in Fig. 2. Under the activation of UV light, the electrons of emitter are excited from the ground state to the conduction band or the excited state near the conduction band, subsequently, the electrons are captured by the traps through the conduction band (process 1). Once ceased the excitation, the electrons escape from the traps and re-enter the conduction band under the stimulation of external factors, recombining with emitter to emit PersL (process $1^{\prime}$ ) [25].
Upon the stimulus of LED light, the electrons of emitter are excited from the ground state to the corresponding excited state. Subsequently, the electrons are captured by surrounding traps through the quantum tunneling (process 2). Once stopped the stimulation, the electrons in the trap are recombined with emitter through quantum tunneling, emitting PersL (process $2^{\prime}$ ) [26]. The PersL mechanism of X-ray or $980 \mathrm{~nm}$ laser excitation is similar to the above-mentioned mechanisms, except that there is a process of energy transfer under X-ray or $980 \mathrm{~nm}$ laser excitation. The excitation energy of X-ray or $980 \mathrm{~nm}$ laser is transferred to the emitter through the host or $\mathrm{Yb}^{3+}-\mathrm{Er}^{3+}$ / $\mathrm{Yb}^{3+}-\mathrm{Tm}^{3+}$ causing the above-mentioned series of electrons transition, capture, release, and recombination of the emitter, and finally produce PersL $[22,27]$. So far, the mechanism for radiopharmaceuticals is still unclear. However, most of radiopharmaceuticals can emit gamma radiation and Cerenkov luminescence during the decay of radionuclides[28, 29], where gamma ray is similar to $\mathrm{X}$-ray but come from different parts of the atom [30], and Cerenkov luminescence have the emission in the range of 250-600 nm [29], thus we speculate that the mechanism of radiopharmaceuticals-excited PersL includes the PersL mechanisms of X-ray, UV light, and LED light.

\section{Synthesis of PLNPs}

The traditional PersL materials are mainly synthesized by solid-state reaction at high temperature [9]. Despite the advantages of high crystallization, strong luminescence, and long PersL time, the irregular morphology and large particle size limit their biomedical application. To obtain nano-sized PLNPs, researchers have

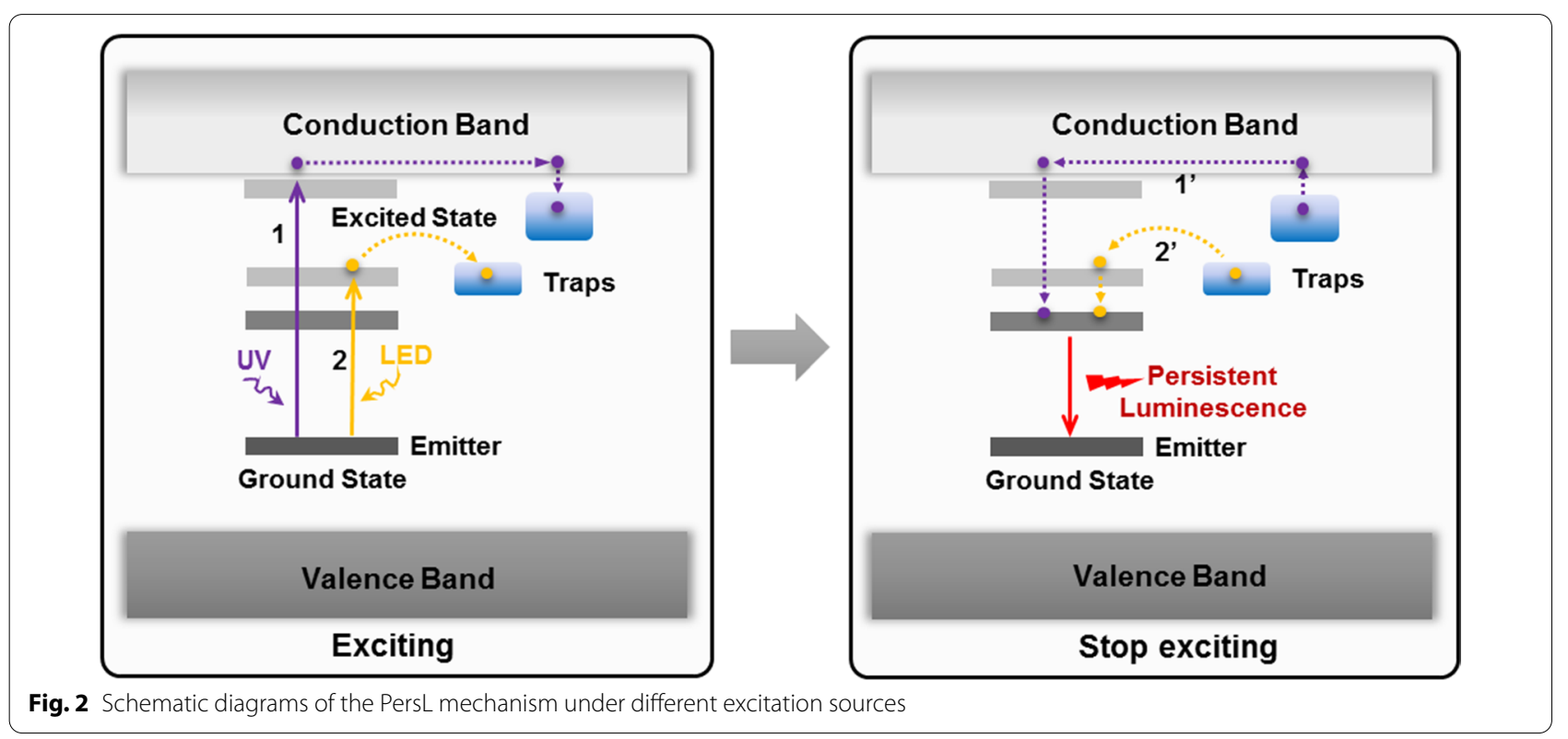


been exploring and improving the synthesis methods of PLNPs for more than a decade. At present, the synthesis methods of PLNPs commonly used in biomedical applications mainly include sol-gel method, template method, hydrothermal/solvothermal method, and cosynthesis method (Table 1 ).

Sol-gel method is to first hydrolyze the precursor into sol, and then transform the sol into gel for subsequent calcination $\left(800-1100{ }^{\circ} \mathrm{C}\right)$, resulting in PLNPs with high yield and small size. Scherman et al. synthesized a series of silicate PLNPs by sol-gel method, such as $\mathrm{Ca}_{0.2} \mathrm{Zn}_{0.9} \mathrm{Mg}_{0.9} \mathrm{Si}_{2} \mathrm{O}_{6}: \mathrm{Eu}^{2+}, \mathrm{Dy}^{3+}{ }_{,} \mathrm{Mn}^{2+}$ [31], $\quad \mathrm{CaMgSi}_{2} \mathrm{O}_{6}: \mathrm{Eu}^{2+}, \mathrm{Mn}^{2+}, \mathrm{Pr}^{3+}$ $\mathrm{Sr}_{1.6} \mathrm{Mg}_{0.3} \mathrm{Zn}_{1.1} \mathrm{Si}_{2} \mathrm{O}_{7}: \mathrm{Eu}^{2+}, \mathrm{Dy}^{3+}$ $\mathrm{Ca}_{1.86} \mathrm{Mg}_{0.14} \mathrm{ZnSi}_{2} \mathrm{O}_{7}: \mathrm{Eu}^{2+}{ }^{2} \mathrm{Dy}^{3+} \quad$ [43], $\quad \mathrm{Sr}_{2} \mathrm{MgSi}_{2} \mathrm{O}_{7}: \mathrm{Eu}^{2+}$, $\mathrm{Dy}^{3+}[44]$. In addition, gallate PLNPs, such as $\mathrm{LiGa}_{5} \mathrm{O}_{8}: \mathrm{Cr}^{3+}[45$, 46], $\mathrm{Zn}_{2.94} \mathrm{Ga}_{1.96} \mathrm{Ge}_{2} \mathrm{O}_{10}: \mathrm{Cr}^{3+}, \mathrm{Pr}^{3+}$ and $\mathrm{Zn}_{1.1} \mathrm{Ga}_{1.8} \mathrm{Ge}_{0.1} \mathrm{O}_{4}: \mathrm{Cr}^{3+}$ $[25,47]$ were also synthesized by sol-gel method, respectively. Sol-gel method has become one of the most commonly used synthesis methods of PLNPs. However, the synthetic products still suffer from inhomogeneous morphology, uncontrollable size, and poor dispersion.

Template method is to use mesoporous silica or carbon nanospheres as a template to bind with precursor ions and then obtain monodisperse, regular morphological PLNPs upon low-temperature calcination. The morphology and particle size of PLNPs can be controlled by the template. Zhang and co-workers have done fruitful work in synthesizing PLNPs by template method. They used mesoporous silica, hollow silica, or carbon nanospheres as a template to controlled synthesize PLNPs, respectively, such as $\mathrm{SiO}_{2} @ \mathrm{Zn}_{2} \mathrm{SiO}_{4}: \mathrm{Mn}[48], \quad \mathrm{SiO}_{2} @ \mathrm{SrMgSi}_{2} \mathrm{O}_{6}: \mathrm{Eu}_{0.01}, \mathrm{Dy}_{0.02}$ [33], $\mathrm{SiO}_{2} @ \mathrm{CaMgSi}_{2} \mathrm{O}_{6}: \mathrm{Eu}^{2+}, \mathrm{Pr}^{3+}, \mathrm{Mn}^{2+}$ [49], $\mathrm{SiO}_{2} @$ $\mathrm{CaTiO}_{3}: \operatorname{Pr}[50], \quad \mathrm{Gd}_{2} \mathrm{O}_{3} @ \mathrm{mSiO}_{2} @ \mathrm{CaTiO}_{3}: \mathrm{Pr} \quad$ [51], $\mathrm{Zn}_{1.1} \mathrm{Ga}_{1.8} \mathrm{Ge}_{0.1} \mathrm{O}_{4}: \mathrm{Cr}^{3+}, \mathrm{Eu}^{3+} \quad @ \mathrm{SiO}_{2}[32], \quad \mathrm{mSiO}_{2} @$ $\mathrm{Gd}_{3} \mathrm{Ga}_{5} \mathrm{O}_{12}: \mathrm{Cr}^{3+}, \mathrm{Nd}^{3+}$ [34], $\mathrm{ZnGa}_{2} \mathrm{O}_{4}: \mathrm{Cr}^{3+} @ \mathrm{HMS}[52]$, ZGOCS@MSNs@ $\mathrm{Gd}_{2} \mathrm{O}_{3}$ [53], and $\mathrm{ZnGa}_{2} \mathrm{O}_{4}: \mathrm{Cr}^{3+}$ [54]. These PLNPs have regular spherical morphology, good monodispersity, and 50-500 $\mathrm{nm}$ particle size, and NIR PersL, which is very suitable for biomedical applications. Although this method has some limitation to prepare ultrasmall PLNPs, it is still considered as a facile way to make nanocarriers for PersL imaging-guided drug delivery.
Hydrothermal/solvothermal method refers to the preparation of nanomaterials by treating the precursors in a sealed heated solution above ambient temperature and pressure [55]. This method has the advantages of mild synthesis conditions and low agglomeration. Importantly, the synthesized PLNPs have ultrasmall size and facile surface modification. Han et al. report a direct hydrothermal synthesis route for $\mathrm{ZnGa}_{2} \mathrm{O}_{4}: \mathrm{Cr}^{3+}$, which has $8 \mathrm{~nm}$ size and stable colloidal property [56]. Zhang et al. employed this method to synthesize $\mathrm{ZnGa}_{2} \mathrm{O}_{4}: \mathrm{Cr}, \mathrm{Eu}$ [36] and $\mathrm{Zn}_{2} \mathrm{SnO}_{4}: \mathrm{Cr}, \mathrm{Eu}$ [57] which have rich surface groups and ultrasamll-size $(<10 \mathrm{~nm})$. Yuan et al.[37] reported hydrothermal synthesis of $\mathrm{Zn}_{1+\mathrm{x}} \mathrm{Ga}_{2-2 \mathrm{x}} \mathrm{Ge}_{\mathrm{x}} \mathrm{O}_{4}: \mathrm{Cr}$, where the size and PersL are fine-tuned by simply changing the amount of Ge. Although these PLNPs have better advantages in particle size, dispersibility, and surface modification, the prepared PLNPs still face the challenge of weak brightness and short PersL time, which need to be further improved.

Co-synthesis method was reported to synthesize PLNPs with small-size and bright PersL by combining the strengths and weaknesses of each of these approaches. Richard et al. reported the synthesis of $\mathrm{ZnGa}_{2} \mathrm{O}_{4}: \mathrm{Cr}^{3+}$ by co-synthesis method, which was firstly synthesized the PLNPs precursor by hydrothermal method, and then calcinated at $750{ }^{\circ} \mathrm{C}$ to enhance the PersL properties [38]. Yan et al. synthesized the precursor by adding cetyltrimethylammonium bromide (CTAB) into the hydrothermal system as the morphology and particle size control agent [39]. With subsequent calcination of the precursor in a short time, $\mathrm{Zn}_{1.25} \mathrm{Ga}_{1.5} \mathrm{Ge}_{0.25} \mathrm{O}_{4}: \mathrm{Cr}^{3+}, \mathrm{Yb}^{3+}, \mathrm{Er}^{3+}$ with around $50 \mathrm{~nm}$ of particle size was synthesized, which had good monodispersity and super-long PersL time. Zhang et al. reported a simple EDTA-etching strategy for regulating the size, dispersibility, and PersL of $\mathrm{ZnGa}_{2} \mathrm{O}_{4}: \mathrm{Cr}$ [58]. The EDTA etching can not only effectively reduce the particle size of PLNPs, but also enhance the aqueousdispersibility and PersL property. At present, it has been developed as an important synthesis method for PLNPs.

\section{Surface functionalization of PLNPs}

The surface properties of nanomaterials have an important influence on their biomedical applications [59-62].

Table 1 Comparison of synthesis methods of PLNPS

\begin{tabular}{|c|c|c|c|c|c|c|}
\hline Synthesis methods & Size $(n m)$ & Morphology & Uniformity & Surfaces group & PersL time & Refs. \\
\hline Sol-gel method & $50-100$ & Bad & $\mathrm{Bad}$ & Lack & Long & {$[25,31]$} \\
\hline Template method & $50-500$ & Good & Good & Lack & Medium & [32-34] \\
\hline $\begin{array}{l}\text { Hydrothermal/solvothermal } \\
\text { method }\end{array}$ & $5-20$ & Good & Good & Abundance & Short & [35-37] \\
\hline Co-synthesis method & $20-60$ & Medium & Medium & Lack & Long & [38-40] \\
\hline
\end{tabular}


Most PLNPs are synthesized under calcination, contributing to a lack of modifiable groups on their surfaces. Therefore, surface functionalization of PLNPs is necessary for further biomedical applications. The surface functionalization could endow the following benefits, (i) increase the biocompatibility of PLNPs and reduce their biological toxicity. (ii) increase the stability in physiological solutions and reduce agglomeration. (iii) provide functional groups (e.g. amine, carboxyl) with further biofunctional molecules attachment for enhancing tumor targeting [60]. In this section, we summarize the two commonly used surface functionalization methods for PLNPs: hydroxylation and silicon coating.

Hydroxylation is a commonly used surface modification method for PLNPs, which is mainly achieved by erosion of $\mathrm{NaOH}$ on the surface of PLNPs. Richard et al. firstly reported the modification process of surface hydroxylation with $\mathrm{NaOH}$ on $\mathrm{Ca}_{0.2} \mathrm{Zn}_{0.9} \mathrm{Mg}_{0.9} \mathrm{Si}_{2} \mathrm{O}_{6}$ : $\mathrm{Eu}^{2+}, \mathrm{Dy}^{3+}, \mathrm{Mn}^{2+}$ and $\mathrm{ZnGa}_{2} \mathrm{O}_{4}: \mathrm{Cr}^{3+}$, and then do the amino by reacting the hydroxyl groups with (3-Aminopropyl)triethoxysilane (APTES) [38, 63]. This method makes their surface amination for further easily conjugating various biofunctional molecules, such as folic acid (FA) [32], peptide [25], polyethylene glycol (PEG) [64, 65], DNA [37], bovine serum albumin (BSA) [54, 66], hyaluronic acid (HA) [67], and antibody [68]. Hydroxylation has become a standard modification method for various PLNPs.

Silica coating is another important method of surface functionalization of PLNPs. Shen et al. used tetraethyl orthosilicate (TEOS) hydrolysis and CTAB as templates to coat mesoporous silicon on the surface of $\mathrm{LiGa}_{5} \mathrm{O}_{8}: \mathrm{Cr}^{3+}$ [69]. Wang et al. used the Stöber sol-gel process to coat silica on the surface of $\mathrm{ZnGa}_{2} \mathrm{O}_{4}: \mathrm{Cr}^{3+}, \mathrm{Sn}^{4+}$ [40]. Wang et al. used Stöber sol-gel process and hydrothermal method to coat silica on the surface of $\mathrm{Zn}_{1.25} \mathrm{Ga}_{1.5} \mathrm{Ge}_{0.25} \mathrm{O}_{4}: \mathrm{Cr}^{3+}, \mathrm{Yb}^{3+}, \mathrm{Er}^{3+}$ [70]. Silica coating provides the good biocompatibility of PLNPs, as well as grants with an easily modified surface, which facilitates the subsequent modification of various biofunctional molecules. To prevent the drug leakage during blood circulation and enhance the tumor-targeting ability, cell membrane vesicles from red blood cells [70], cancerous cells [71, 72], and lactobacillus reuteri [73] are used to camouflage on the silica coating PLNPs, which have the superior abilities of immune escape and tumor adhesion.

\section{Toxicity studies of PLNPs}

The influencing factors of the biological toxicity of nanomaterials mainly include: (i) the stability, (ii) the morphology and particle size, (iii) the surface properties [74-77]. At present, the PLNPs for the biomedical application have biocompatible concerns due to the prolonged retention in normal tissue. Thus, a well understanding of the pharmacokinetics and biosafety issue of PLNPs in biological systems can greatly promote the biomedical applications of PLNPs for future clinical translation.

To date, various cell lines have been used to evaluate the in vitro cytotoxicity of different PLNPs. Most of the results indicated that the PLNPs had no obvious cytotoxicity. Yan and Richard et al. studied the in vitro cytotoxicity of the PEGylated and amination PLNPs, respectively. The results showed that the cancerous cells were exposed to PLNPs at concentrations up to $1 \mathrm{mg} / \mathrm{mL}$ for 24 or $48 \mathrm{~h}$ without significant effects on cell viability $[25,38]$. Zhang et al. exposed the amination PLNPs to different cell lines, and the results of cell viability and apoptosis showed low cytotoxicity of PLNPs [32, 36]. In addition, Zhang et al. selected three types of cells to systematically evaluate the in vitro risk of the PEGylated PLNPs [78]. Results showed that the PEGylated PLNPs had no significant effect on cell viabilities, cell membrane damage, oxidative stress, and apoptosis of three different cell lines.

For further applications of PLNPs in the biomedical field, the most important problem is the in vivo biodistribution and toxicity of PLNPs. Liu et al. evaluated the hemocompatibility of pristine PLNPs and PEGylated PLNPs [79]. Results showed that the pristine PLNPs can cause hemolysis, erythrocyte aggregation and morphology changes, and a prolonged coagulation effect, and that these side effects are alleviated by PEGylation. Besides, both pristine PLNPs and PEGylated PLNPs are well tolerated to the risk of complement-activated thrombosis and inflammation. Martínez-Alfaro et al. studied the in vivo toxicity of hydroxylated and PEGylated PLNPs at different concentrations within 6 months [80]. Results showed that no toxic effects were detected at doses of hydroxylated PLNPs $\sim 2 \mathrm{mg} /$ mouse classically used for biological imaging. Similarly, no toxic effects could be evidenced on any of the groups treated with PEGylated PLNPs across the range of tested concentrations. The distribution and metabolism of PLNPs in vivo have an important influence on their toxicity. Richard et al. reported the influence of particle size, surface state, and physicochemical properties on PLNPs biological fate in vivo $[63,81]$. The results demonstrate that masking charges, increasing the aminosilane density, and reducing the particle size can reduce the capture of PLNPs by the liver and effectively increase the circulation time of PLNPs in vivo. Unlike other fluorescent nanoprobes, the PersL of PLNPs can persist for a long time after excitation, and there is a risk of double exposure of nanoparticles and PersL for in vivo applications. Zhang et al. systematically studied the potential risk of nanoparticles and PersL of PLNPs 

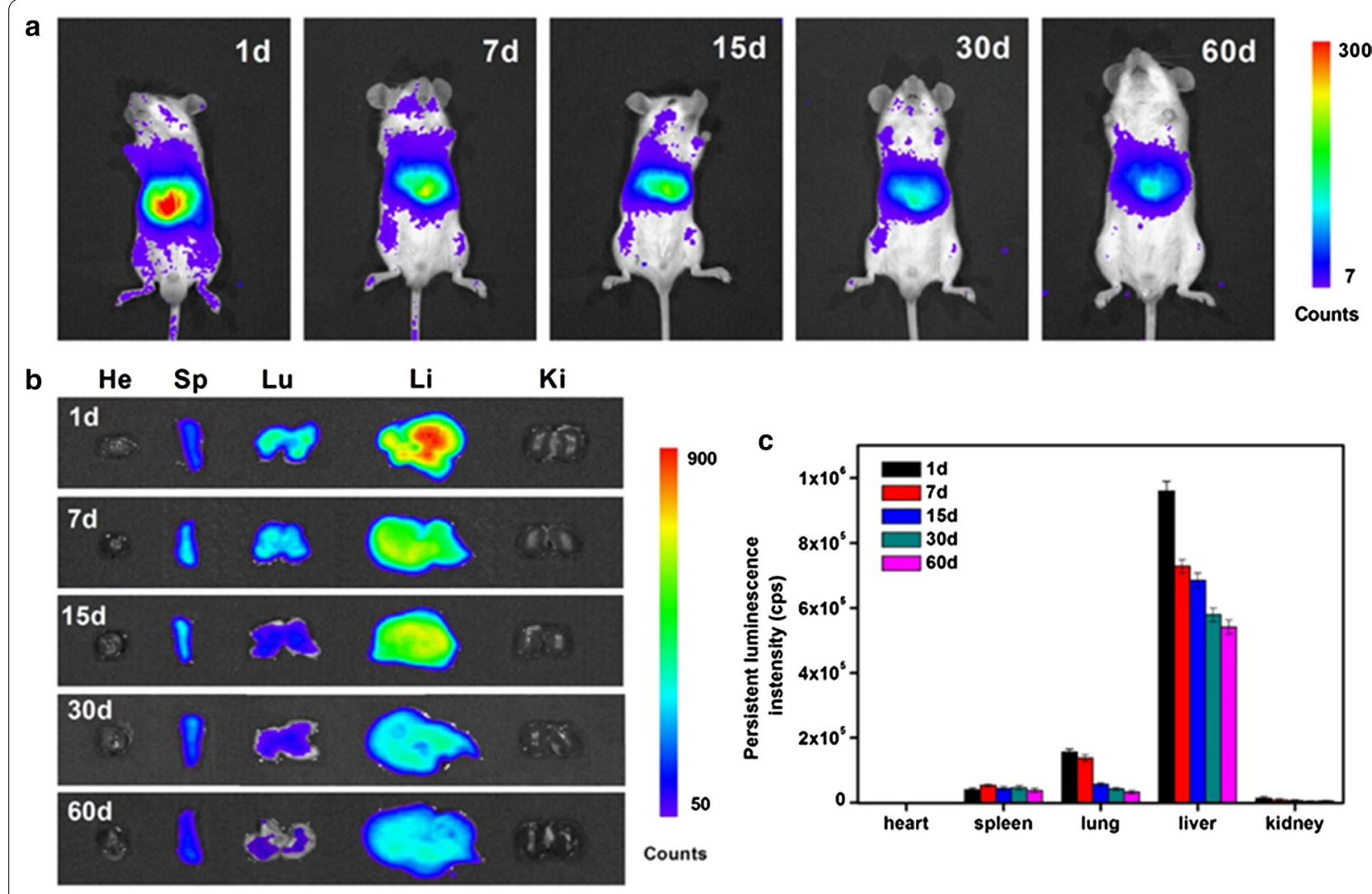

Fig. 3 a In vivo biodistribution of PEGylated PLNPs at different time points. b Ex vivo distribution of PEGylated PLNPs in vital organs at different time points. c PersL intensities of PEGylated PLNPs collected from isolated organs at different time points. (Reproduced with permission [78]. Copyright 2018, Nature Publishing Group)

within 2 months (Fig. 3) [78]. After intravenous injection of $10 \mathrm{mg} / \mathrm{kg}$ PEGylated PLNPs, most of them accumulated in the reticuloendothelial system and could be gradually cleared out of the body through the digestive system. Besides, neither the PEGylated PLNPs nor the PersL showed significant toxicity in mice over 2 months. Although more careful toxicology studies are necessary for example the effect of PLNPs on the gene, protein or to evaluate their biotransformation, the lack of obvious toxicity shown in the above studies encourages future development of PLNPs for in vivo biomedical research.

\section{In vivo bioimaging}

\section{In vivo PersL imaging}

Encouraged by the strength of PLNPs, such as the long afterglow, background-free autofluorescence, high sensitivity, and deep tissue penetration, PLNPs are highly suitable for in vivo autofluorescence-free optical imaging. We discuss the in vivo PersL imaging of tumors by different excitation sources, including UV, LED, NIR laser, X-ray, and radiopharmaceutical.

\section{UV pre-excitation}

In 2007, Scherman et al., for the first time, applied PEGylated $\mathrm{Ca}_{0.2} \mathrm{Zn}_{0.9} \mathrm{Mg}_{0.9} \mathrm{Si}_{2} \mathrm{O}_{6}: \mathrm{Eu}^{2+}, \mathrm{Dy}^{3+}, \mathrm{Mn}^{2+}$ for in vivo PersL imaging of tumor-bearing mice [30]. After pre-excitation of PLNPs by UV lamp, the intravenously injected PLNPs were accumulated to the tumor region in 2 min, which was easily visualized by the PersL signal. Subsequently, Yan et al. synthesized $\mathrm{Cr}^{3+}, \mathrm{Pr}^{3+}$ codoped $\mathrm{Zn}_{2.94} \mathrm{Ga}_{1.96} \mathrm{Ge}_{2} \mathrm{O}_{10}$ with almost 15 days of NIR PersL [25]. After surface modification of PEG and tumor targeting molecule RGD, the PLNPs can actively target to tumor region, visualized by high sensitive PersL imaging in 20 min (Fig. 4a). Besides, Yuan et al. constructed DNA aptamer modified $\mathrm{Zn}_{1.2} \mathrm{Ga}_{1.6} \mathrm{Ge}_{0.2} \mathrm{O}_{4}$ : $\mathrm{Cr}$ nanoparticles (ZGGO:Cr-Apt) with long-lasting luminescence and good tumor-specific binding property [37]. Thus the autofluorescence-free targeted imaging of tumors was captured even until $5 \mathrm{~h}$ postinjection of ZGGO:Cr-Apt 

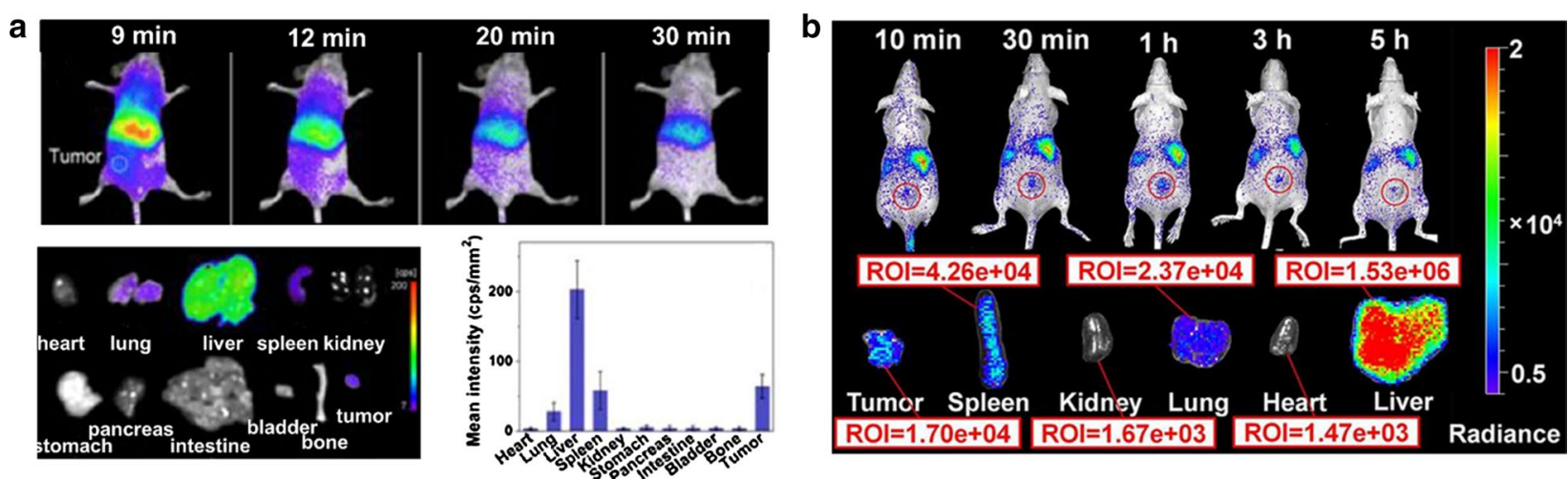

Fig. 4 a In vivo and ex vivo PersL images of tumor-bearing mice postinjection with RGD-LPLNPs. Reproduced with permission [25]. Copyright 2013 American Chemical Society. b In vivo and ex vivo PersL imaging of tumor-bearing mice postinjection with ZGGO:Cr-Apt. (Reproduced with permission [37]. Copyright 2017 American Chemical Society)

(Fig. 4b). However, due to the slow tumor accumulation of PLNPs and the relatively short afterglow-time of preexcited PLNPs, thus the in vivo PersL imaging of tumor using UV pre-excited PLNPs usually happens at the beginning time of postinjection, which are not suitable for long-term tracking of tumors.

\section{LED in situ excitation}

Richard et al. first employed an orange/red LED as in situ excitation source for in vivo PersL imaging of tumors using PEG-modified $\mathrm{ZnGa}_{2} \mathrm{O}_{4}: \mathrm{Cr}^{3+}$ nanoparticles [64]. The UV pre-excited PLNPs were intravenously injected for in vivo tumor PersL imaging at $2 \mathrm{~h}$. After the PersL signal of the tumor site is decayed, the red LED was used for in-situ re-excitation, which can restore the PersL signal of the tumor site and realize in vivo reexcitation imaging of the tumor (Fig. 5). Later, Pan et al. intravenously injected $\mathrm{c}(\mathrm{RGDyK})$ peptide conjugated $\mathrm{LiGa}_{5} \mathrm{O}_{8}: \mathrm{Cr}^{3+}$ in $4 \mathrm{~T} 1$ tumor model and used white LED to in situ stimulate tumor accumulated $\mathrm{LiGa}_{5} \mathrm{O}_{8}: \mathrm{Cr}^{3+}$ for PersL imaging up to $24 \mathrm{~h}$ [45]. Besides, Yan et al. reported FA modified $\mathrm{Zn}_{1.25} \mathrm{Ga}_{1.5} \mathrm{Ge}_{0.25} \mathrm{O}_{4}: \mathrm{Cr}^{3+}, \mathrm{Yb}^{3+}, \mathrm{Er}^{3+}$ for actively targeting of MCF-7 tumor by oral administration [39]. With the excitation of $650 \mathrm{~nm}$ LED, the tumor regions achieve long time (160 $\mathrm{min})$ and high sensitive (SNR > 20) PersL imaging. However, deep tissue imaging is still difficult to be achieved due to the limitations of the LED's own visible wavelength.

\section{NIR laser excitation}

The light located in the biological window has better tissue penetration and is suitable for deep tissue reactivation [82, 83]. Therefore, rare-earth doped PLNPs have been developed for NIR laser excitation. Zhang et al. reported that the ultrasmall $\mathrm{ZnGa}_{2} \mathrm{O}_{4}: \mathrm{Cr}, \mathrm{Eu}$ and $\mathrm{Zn}_{2} \mathrm{SnO}_{4}: \mathrm{Cr}$,Eu can be easily modified with folic acid molecules through a simple condensation reaction [36, 84]. Highly sensitive targeted imaging of tumor can be achieved by injecting ultraviolet pre-excited PLNPs into mice. After the signal of the tumor site is decayed, the tumor site was re-excited or re-stimulated by the light source of $808 \mathrm{~nm}$ with stronger tissue penetration, which can achieve high sensitive tumor imaging. Hao et al. reported a novel $980 \mathrm{~nm}$ laser-activated upconverted PLNPs $\left(\mathrm{Zn}_{3} \mathrm{Ga}_{2} \mathrm{GeO}_{8}: \mathrm{Yb} /\right.$ $\mathrm{Er} / \mathrm{Cr}$ ) for in vivo PersL imaging (Fig. 6). Owing to the efficient energy transfer $\left(\mathrm{Er}^{3+}-\mathrm{Cr}^{3+}\right)$, the produced NIR PersL remained up to $15 \mathrm{~h}$. Meanwhile, these upconverted PLNPs also can be effectively recharged in vivo under $980 \mathrm{~nm}$ laser's excitation [85]. Chang et al. developed $\left(\mathrm{Zn}_{2} \mathrm{SiO}_{4}: \mathrm{Mn}\right): \mathrm{Y}^{3+}, \mathrm{Yb}^{3+}, \mathrm{Tm}^{3+}$ upconverting PLNPs for deep tumor imaging under $980 \mathrm{~nm}$ laser [86]. Besides, Li et al. constructed hybrid nanoparticles composed of upconversion nanoparticles and PLNPs, which can be excited by a $980 \mathrm{~nm}$ laser and showed PersL emission at $700 \mathrm{~nm}$ to realize NIR to NIR upconverted PersL imaging [87]. However, NIR laser as the excitation source for upconverted PLNPs still has some challenges to obtain deep tissue imaging due to the much weaker PersL generated from upconverted PLNPs.

\section{$X$-ray excitation}

X-ray has been as an innovative excitation source for in vivo optical imaging in recent years as the excellent merits of negligible scattering and deep depth penetration [88]. Some phosphors can be activated by X-ray photons to generate light by triggering the luminescent centers. Yang et al. firstly proposed X-ray as external optical excitation to activate PEG-functionalized $\mathrm{SrAl}_{2} \mathrm{O}_{4}: \mathrm{Eu}^{2+}$ PLNPs for imaging deep tissue (up to $2.5 \mathrm{~cm}$ ) [65]. Hao et al. employed X-ray to activate 


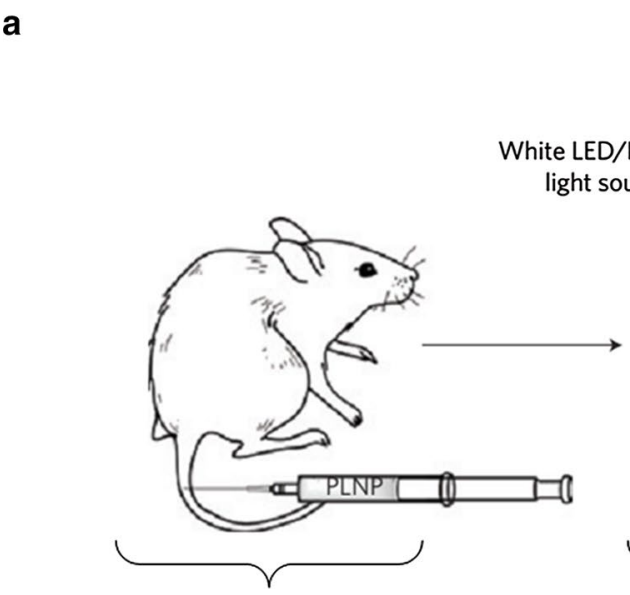

Injection of red-excitable persistent luminescence nanoparticles

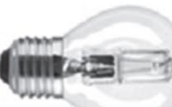

en

\{

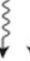

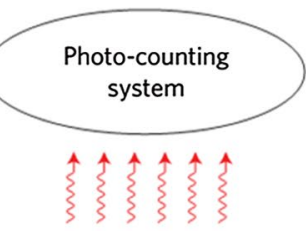

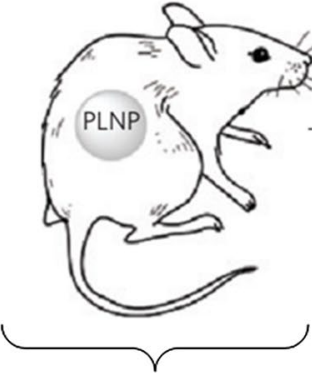

In situ activation of persistent luminescence

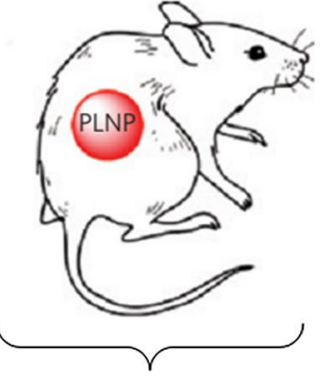

Detection of NIR persistent luminescence b

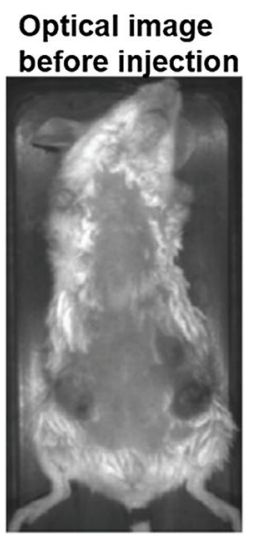

\section{UV pre-exited PersL image}

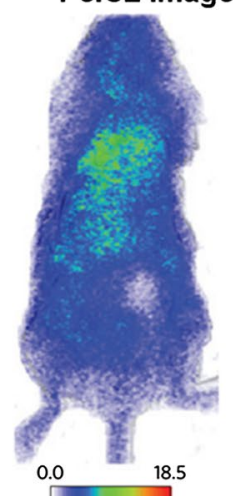

LED re-exited PersL image

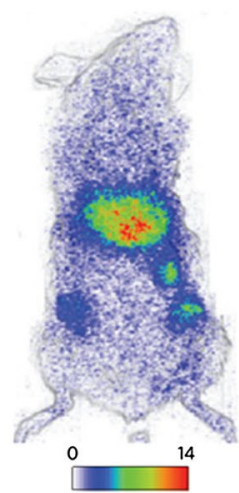

C

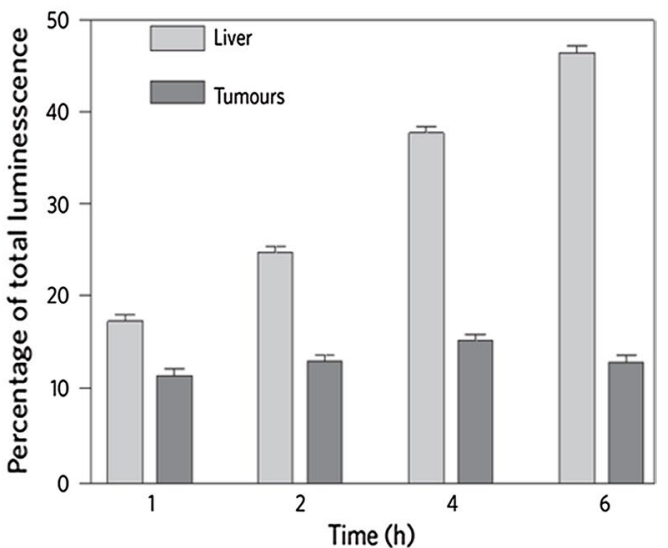

Fig. 5 a A scheme for in vivo rechargeable Pers L imaging based on LED-activated $\mathrm{ZnGa}_{2} \mathrm{O}_{4}: \mathrm{Cr}^{3+}$. b Optical image of a 3-tumor-bearing mouse at preinjection, $2 \mathrm{~h}$ post-injection of pre-excited ZGO-PEG, and $4 \mathrm{~h}$ post-injection but re-excited with LED. $\mathbf{b}$ PersL intensities of liver and tumors measured from the whole mice at different time points. (Reproduced with permission [64]. Copyright 2014 Nature Publishing Group)

$\mathrm{ZnGa}_{2} \mathrm{O}_{4}$ :Cr PLNPs for renewable NIR PersL imaging of deep-tissue [89]. To synthesize the controllable morphology of PLNPs, Yang et al. developed kiwifruit-like structures of $\mathrm{SiO}_{2} @ \mathrm{ZnGa}_{2} \mathrm{O}_{4}: \mathrm{Cr} @ \mathrm{SiO}_{2}$ with the assistant of silica template. Then the X-ray irradiated PLNPs showcased the excellent PersL performance and longterm imaging from deep tissue [90]. Zhang et al. designed $\mathrm{MgGeO}_{3}: \mathrm{Mn}^{2+}, \mathrm{Yb}^{3+}, \mathrm{Li}^{+}$(MGO) PLNPs with NIR-I and NIR-II emission. Under the activation of soft X-rays, MGO can be visualized from deep tissue [91]. Yeh et al. developed PEGylated $\mathrm{ZnGa}_{2} \mathrm{O}_{4}: \mathrm{Cr}^{3+}$ concave nanocubes with highly passive targeting and $\mathrm{X}$-ray excitation for PersL imaging of deep-seated orthotopic hepatic tumors [92]. The uniform nanocubes showed stable NIR radioluminescence after repeated X-ray excitation (Fig. 7a-c)
With the low-dose of X-ray excitation (0.5 Gy), these PEGylated PLNPs clearly depicted the orthotropic hepatic tumors from in vivo and ex vivo PersL imaging (Fig. 7d,e). Despite the superior advantages of deep penetration, the radiation dose from X-ray must be set carefully to avoid radioactive damage in normal tissues.

\section{Radiopharmaceutical excitation}

Radiopharmaceutical can be regarded as an internal excitation light for deep tissue imaging. Many radionuclides possess Cerenkov radiation with blue light as well as gamma radiation during the process of decay [93]. $\mathrm{ZnGa}_{2} \mathrm{O}_{4}: \mathrm{Cr}^{3+}$ have a strong excitation spectrum at the UV region and NIR emission, thus we first reported that $\mathrm{ZnGa}_{2} \mathrm{O}_{4}: \mathrm{Cr}^{3+}$ could be activated by radionuclides with 


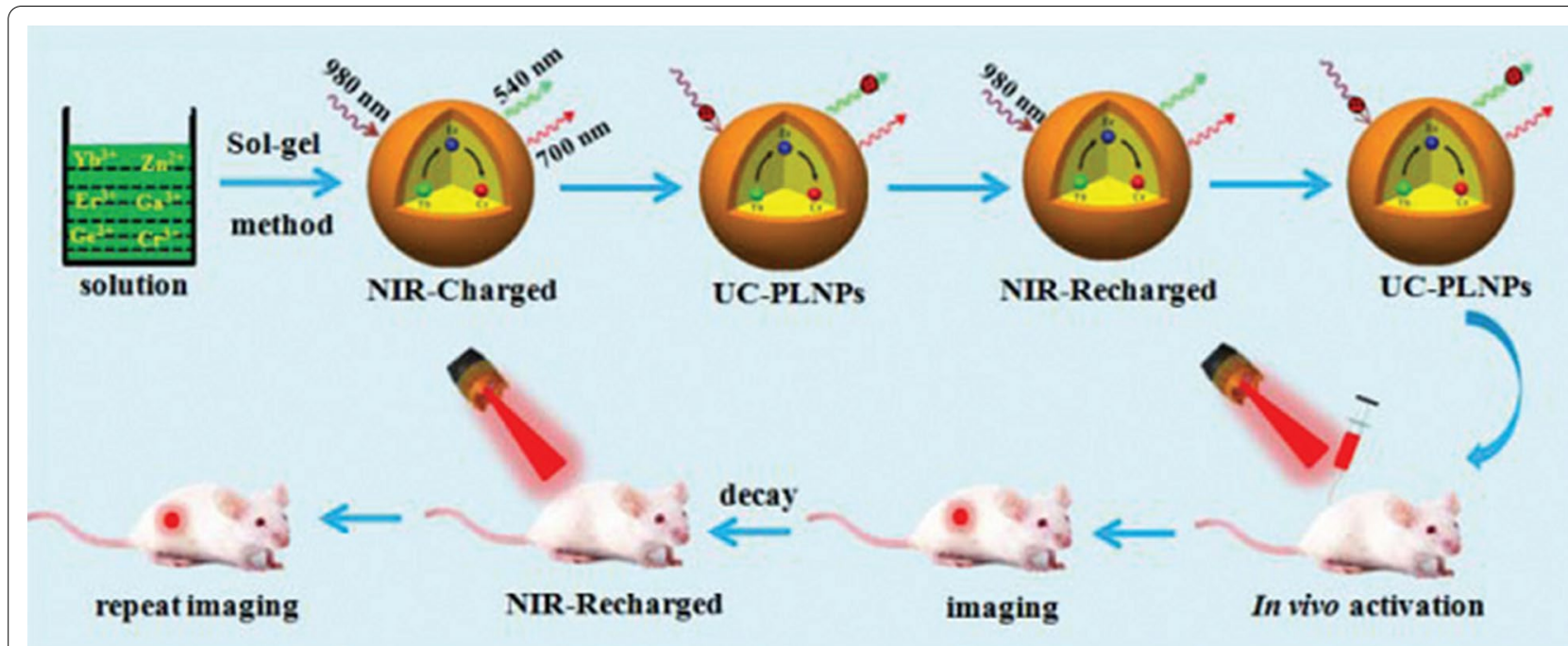

Fig. 6 Schematic illustration of the sol-gel method and NIR-to-NIR rechargeable in vivo bioimaging based on 980 nm laser-activated NIR-emitting UC-PLNPs. (Reproduced with permission [85]. Copyright 2017, Royal Society of Chemistry)
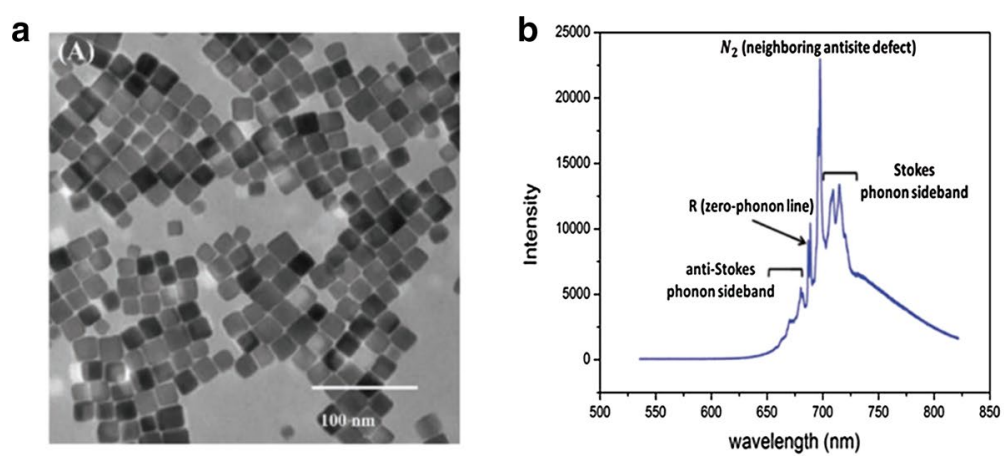

d

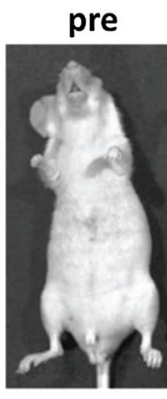

0

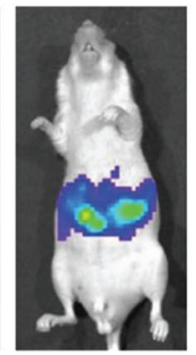

60

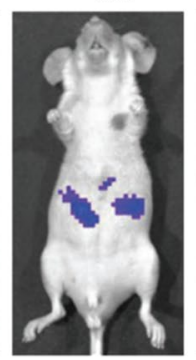

120

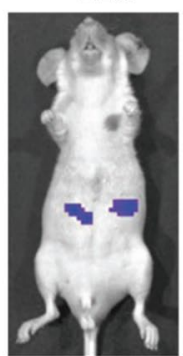

$180 \min$

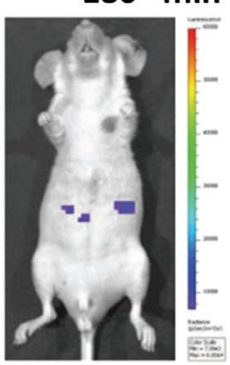

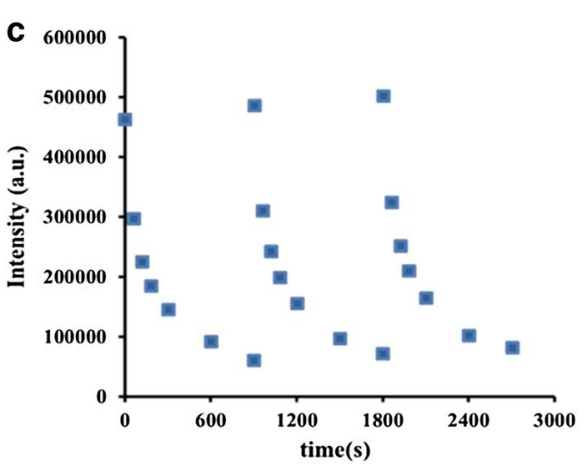

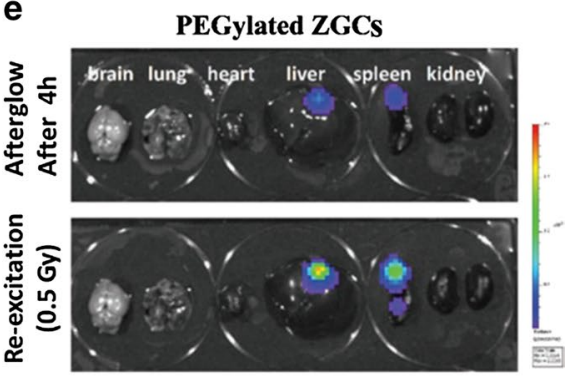

Fig. 7 a, b TEM image and X-ray excited radioluminescence of $\mathrm{ZnGa}_{2} \mathrm{O}_{4}: \mathrm{Cr}^{3+}$ nanocubes. c Rechargeable PersL performance of PEGylated $\mathrm{ZnGa}_{2} \mathrm{O}_{4}: \mathrm{Cr}^{3+}$ nanocubes under $0.5 \mathrm{~Gy}$ X-ray irradiation. $\mathbf{d}$, e In vivo and ex vivo PersL imaging of tumor-bearing mice treated with iv injected $\mathrm{ZnGa}_{2} \mathrm{O}_{4}: \mathrm{Cr}^{3+}$ nanocubes and X-ray irradiation. (Reproduced with permission [92]. Copyright 2019, Wiley-VCH)

NIR emission for deep tumor imaging, where the NIR emission includes radionuclides' excited fluorescence and PersL (Fig. 8a) [28]. Then we utilized FDA-approved ${ }^{18} \mathrm{~F}$-fluorodeoxyglucose $\left({ }^{18} \mathrm{~F}\right.$-FDG) to in vivo stimulate $\mathrm{ZnGa}_{2} \mathrm{O}_{4}: \mathrm{Cr}^{3+}$ for optical imaging of tumor. The PersL signal from ${ }^{18} \mathrm{~F}$-FDG excited $\mathrm{ZnGa}_{2} \mathrm{O}_{4}: \mathrm{Cr}^{3+}$ can remain over $3 \mathrm{~h}$ at the tumor region while very few luminescence from ${ }^{18} \mathrm{~F}$-FDG's treatment was detected (Fig. 8b). Importantly, $\mathrm{ZnGa}_{2} \mathrm{O}_{4}: \mathrm{Cr}^{3+}$ could be efficiently recharged in vivo by multiply injection of ${ }^{18} \mathrm{~F}$-FDG which enables long-lasting tumor imaging with high sensitivity and high ratio of tumor to liver. 


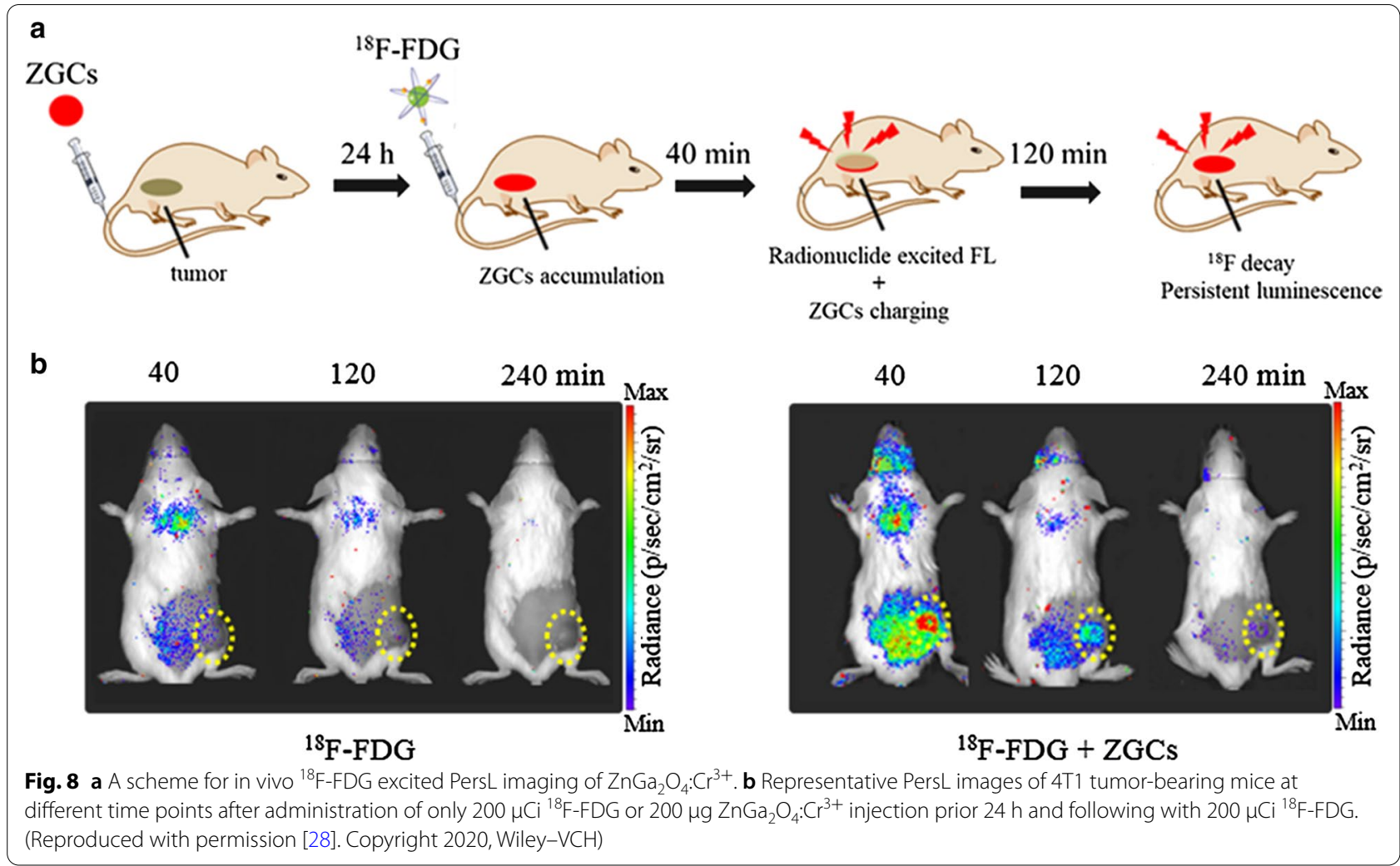

\section{In vivo multimodal imaging}

Multimodal imaging that combines the advantages of different imaging modalities can provide more accurate disease information for precise diagnosis [94]. Therefore, integrating the merits of PLNPs and other image modalities enables to design high-performance PLNPs nanoprobes, such as, X-ray computed tomography (CT), SPECT imaging, magnetic resonance (MR), and photoacoustic imaging (PA) can simultaneously endow physiological information with high spatial resolution, which makes up the limitation from single-modal imaging (PersL).

Three major methods have been proposed to construct PLNPs-based multifunctional nanoprobes. The first strategy focuses on the use of surface chemical modifications to attach another imaging modality. For example, Gao et al. developed c(RGDyK) peptide and radioisotope ${ }^{99 \mathrm{~m}}$ Tc labeled PLNPs for targeted PersL/SPECT imaging of orthotopic breast cancer after oral administration [95]. Yan et al. reported Gd-DTPA modified PLNPs (Gd(III)-PLNPs) for in vivo NIR persistent luminescence and T1-weighted MRI imaging [96]. Besides, Yan et al. employed hyaluronic acid-functionalized $\mathrm{Gd}_{2} \mathrm{O}_{3}$ (HA- $\mathrm{Ga}_{2} \mathrm{O}_{3}$ ) to conjugate on PLNPs [67]. The conjugation not only had the tumor active-targeting capability but also exhibited strong MR and PersL signals in tumor regions. The second method is to introduce the coreshell structured PLNPs by sequential growth or coating. Yan et al. reported the multifunctional core-shell nanostructures $\left(\mathrm{Zn}_{2.94} \mathrm{Ga}_{1.96} \mathrm{Ge}_{2} \mathrm{O}_{10}: \mathrm{Cr}^{3+}, \mathrm{Pr}^{3+} @ \mathrm{TaO}_{\mathrm{x}} @ \mathrm{SiO}_{2}\right)$ for in vivo PersL/CT imaging of tumor [97]. Zhang et al. constructed polypyrrole-coated PLNPs which offered dual-modal PersL/PA imaging of tumors [98]. Wang et al. also presented $\mathrm{GdAlO}_{3}: \mathrm{Mn}^{4+}, \mathrm{Ge}^{4+} @ \mathrm{Au}$ (GAMG@Au) core-shell nanoprobes with MR/CT/PersL third-modals imaging properties [99]. After modified with folic acidPEG-SH, the nanoparticles could actively accumulate at the tumor regions, which were clearly visualized by MR/CT/PersL imaging (Fig. 9). However, this core-shell strategy brings an inevitable size increase and a decreasing PersL owning to the photon reflection or assimilation from shell structure. Finally, the doping approach is much preferable because of the simple preparation and stable physicochemical property. Richard et al. synthesized $\mathrm{ZnGa}_{1.915} \mathrm{Cr}_{0.005} \mathrm{Gd}_{0.08} \mathrm{O}_{4}$ nanoparticles by sintering in the air after hydrothermal crystallization, which allowed the high-sensitive optical detection and high-spatialresolution MR imaging in vivo [100]. Recently, Song et al. also employed the co-synthesis method to prepare $\mathrm{Bi}_{2} \mathrm{Ga}_{4} \mathrm{O}_{9}$ :Cr PLNPs, which enabled X-ray excited PersL imaging as well as Bi-enhanced CT imaging [101]. 
a

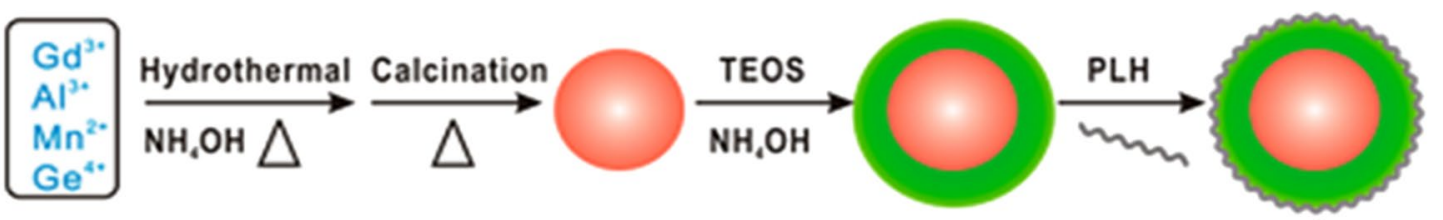

GAMG PLNPS GAMG@SiO,

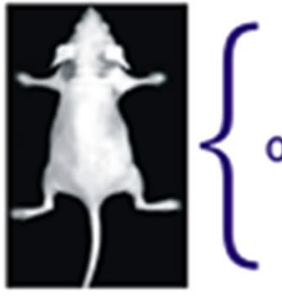

b

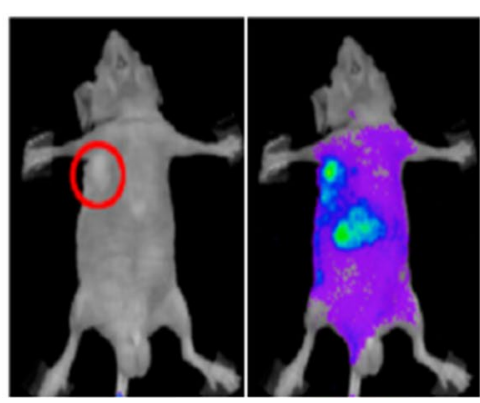

c $\quad 0 \mathrm{~h}$

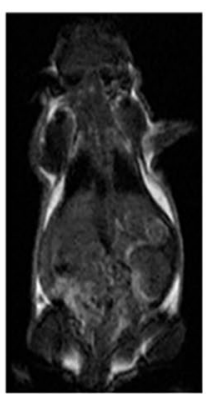

$1 \mathrm{~h}$

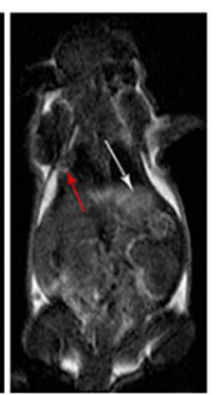

d $\quad 0 h$

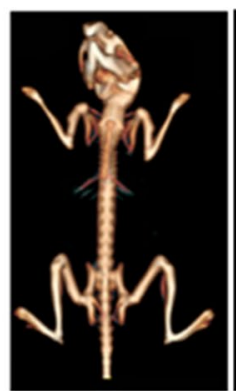

$1 \mathrm{~h}$

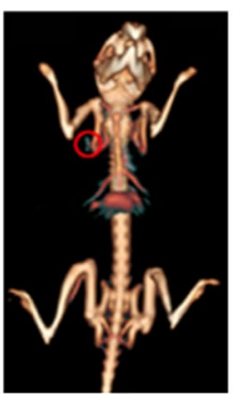

Fig. 9 a Schematic illustration of the synthesis of GAMG@Au core - shell nanostructure for in vivo tri-modal imaging. b-d In vivo PersL/MR/CT images before and after intravenous injection of FA-PEG-GAMG@Au. (Reproduced with permission [99]. Copyright 2016 American Chemical Society)

\section{PLNPs based cancer therapy PLNPs based surgery}

Fluorescence-guided surgery (FGS) uses the realtime fluorescence images of disease to guide surgical operation, which paves a much cheaper and easier way for precise resection of tumors [37]. FGS can provide real-time imaging during surgery, which is much cheaper and much easier to operate compared to conventional imaging technologies. Due to the excellent advantages of PLNPs (NIR emission, long PersL, and high signal-to-background ratio), Tian et al. employed $\mathrm{ZnGa}_{2} \mathrm{O}_{4}: \mathrm{Cr}^{3+}$ for the long-term image-guided surgery of hepatocellular carcinoma (HCC) [102]. These $\mathrm{ZnGa}_{2} \mathrm{O}_{4}: \mathrm{Cr}^{3+}$ were prepared following a reported method [56]. Interestingly, there was no uptake of $\mathrm{ZnGa}_{2} \mathrm{O}_{4}: \mathrm{Cr}^{3+}$ by $\mathrm{HCC}$ tumor tissue but a significant uptake by normal liver tissue, allowing for a precise mapping of the HCC tumor area with more radical excision (Fig. 10).

\section{PLNPs based photothermal therapy}

Photothermal therapy (PTT) uses photo-absorbers that absorbs laser energy to produce enough heat to kill cancer cells. Because of the superiority of minimal-invasiveness and spatial specificity, photo-absorbers based PTT has been used in numerous pre-clinical studies [103]. Although PLNPs themselves cannot be used directly in photothermal therapy due to their low extinction coefficient, coupling with NIR absorbing materials (such as ICG, $\mathrm{CuS}$ ) can be achieved for PersL imaging-guided PTT of tumors. Chang et al. designed the PLNPs and ICG co-loaded mesoporous silica for PersL imaging-guided PTT [104]. The constructed nanoplatform had strong NIR absorption with an excellent photothermal response, which showed efficient tumor elimination in vitro and in vivo. Yan et al. developed an activatable PLNPs/CuSbased nanoplatform for PersL imaging-guided PTT [105]. $\mathrm{CuS}$ nanoparticles were regarded as both PTT agents and quencher to afford the high photothermal conversion 


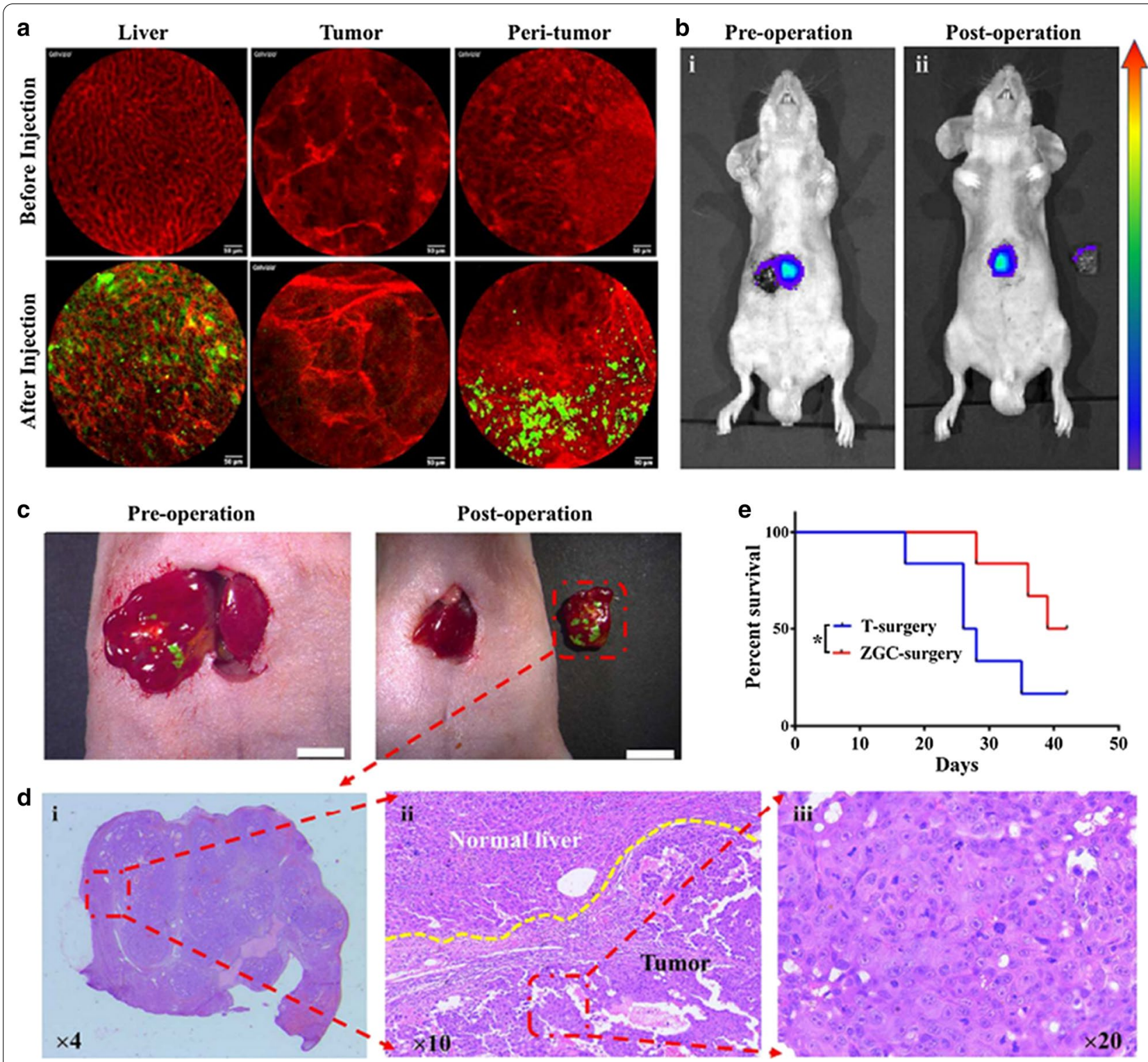

Fig. 10 a Confocal laser endomicroscopic images of liver, tumor, and peri-tumoral area at $6 \mathrm{~h}$ post-injection of $\mathrm{ZnGa}_{2} \mathrm{O}_{4}: \mathrm{Cr}^{3+}$. b PersL images of the exposed tumor lesion following the PLNPs' injection and LED's irradiation. c GFP fluorescence images of the 3 exposed tumor lesions were merged with the white-light images. $\mathbf{d}$ H\&E staining of the resected tissue from $\mathbf{c}$. e The survival rates of mice from different treatments. (Reproduced with permission [102]. Copyright 2018, Elsevier)

efficiency to the whole nanoformulation. Thus the synthesized nanoplatform exhibited highly sensitive PersL imaging of tumors and excellent tumor treatment. Zhang et al. also reported polypyrrole-coated PLNPs which enabled good PersL/PA imaging and efficient photothermal effect on tumor inhibition (Fig. 11) [98].

\section{PLNPs based photodynamic therapy}

Photodynamic therapy (PDT) has been widely used in clinical research and practice to treat most solid tumors due to its non-invasiveness and double selectivity [106, 107]. In general, external light is employed to activate PSs, producing reactive oxygen species (ROS) and damaging cancer cells. However, a major challenge of PDT is the requirement of visible or even UV light for PSs' excitation, where these short-wavelength light sources have limited penetration depth and strong scattering in vivo, leading to the low efficiency of tumor treatment [108]. PLNPs can act as nanocarriers of PSs to achieve effective treatment of tumors, because PLNPs can be excited 


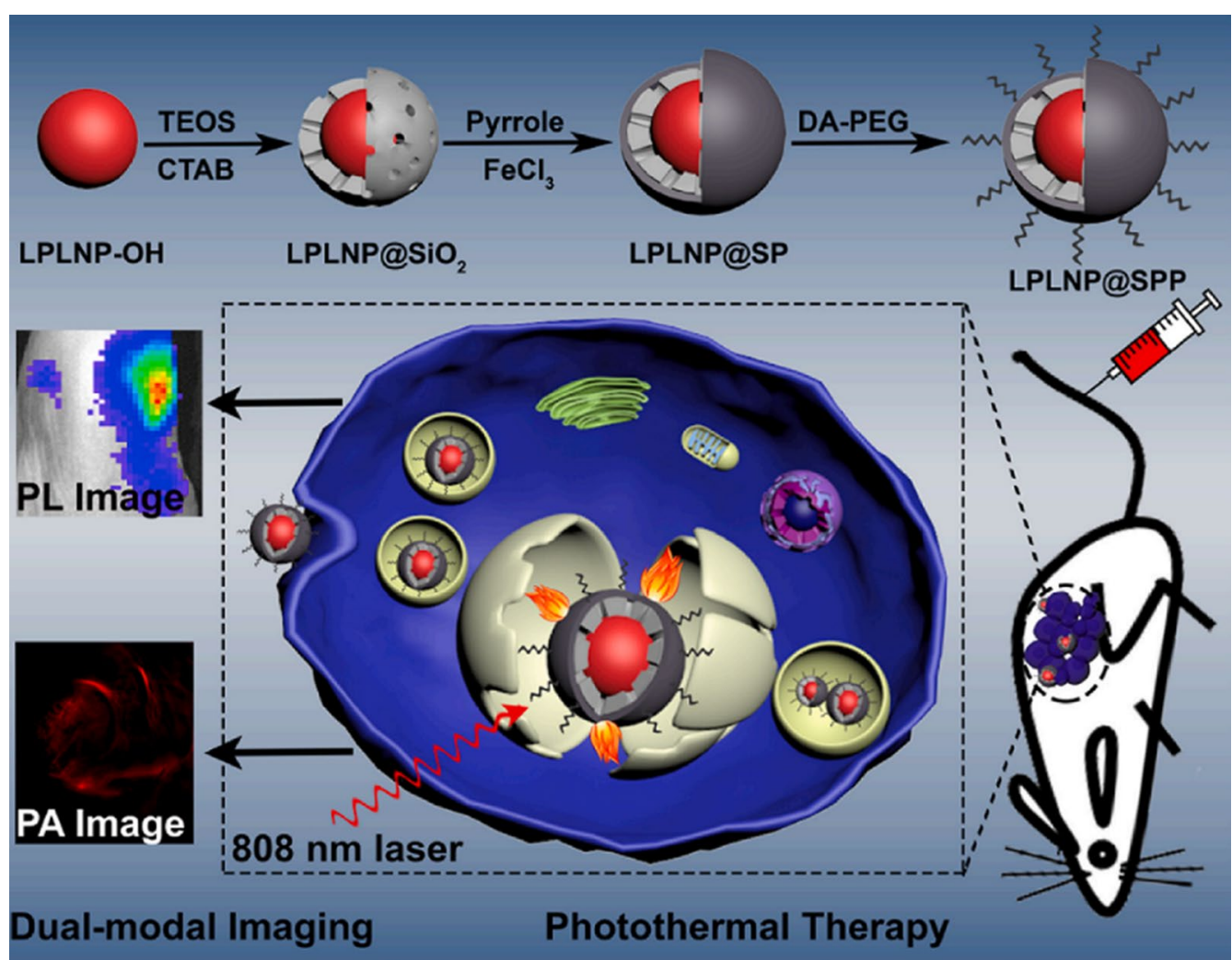

Fig. 11 Schematic diagram of LPLNP@SPP synthesis method, dual-modal imaging-guided PTT. (Reproduced with permission [98]. Copyright 2021, Elsevier)

by other light sources (LED, NIR laser, X-ray, and radiopharmaceuticals) to produce PersL, which in turn activates photosensitizers of corresponding absorption wavelengths and finally produces continuous ${ }^{1} \mathrm{O}_{2}$ to kill cancer cells. Besides, PLNPs remain long-lasting PersL for continuous PSs activation after removing away the excitation source, which can avoid the side effects induced by the prolonged irradiation. Furthermore, PLNPs aid in the loading and delivery of PSs because of the easy surface modification for PSs loading and tumor targeting (Table 2).

Liu et al. prepared sulfonated aluminum phthalocyanine (AlPcS) conjugated $\mathrm{Zn}_{1.25} \mathrm{Ga}_{1.5} \mathrm{Ge}_{0.25} \mathrm{O}_{4}: \mathrm{Cr}^{3+}, \mathrm{Yb}^{3+}, \mathrm{Er}^{3+}$ @ $\mathrm{mSiO}_{2}$ for UV excited PDT of cancer cells [109]. Due to the unavailability of UV excitation for in vivo study, some groups tried to use commercial LED light to excited PLNPs for PSs' activation. Zhang et al. designed hollow $\mathrm{ZnGa}_{2} \mathrm{O}_{4}$ :Cr with high silicon phthalocyanine ( $\mathrm{Si}$ Pc) loading for LED excited in vivo PDT [54]. Liu et al. developed $\mathrm{Bi}^{3+}$ and $\mathrm{Cr}^{3+}$ codoped zinc gallogermanate nanoparticles with enhanced deep red PersL emission and PersL time. After coated with mesoporous silica and loaded Zinc phthalocyanine $(\mathrm{ZnPc})$, red light endowed this nanoplatform for direct excitation of PSs and later discharging PersL's excitation of PSs [110]. Dong et al. proposed to encapsulate $\mathrm{ZnGa}_{2} \mathrm{O}_{4}: \mathrm{Cr}^{3+}$ and IR780 iodine into a temperature-responsive "waxseal" for imaging-guided and localized PDT [111]. The waxseal could prevent luminescence quenching as well as premature initiation of PDT. After photothermal activation, the NIR PersL from PLNPs not only provided high sensitive images of tumors but also continuously excited PSs for reactive oxygen species generation (Fig. 12). To achieve long-term repeatable PLNPs-excited-PDT, PersL implants are proposed to maintain high-dose of PLNPs within tumors. Chen et al. designed injectable PersL implants as an internal excitation source for repeatable LED plus NIR PersLexcited PDT [112]. The implants were synthesized by dissolving $\mathrm{ZnGa}_{2} \mathrm{O}_{4}: \mathrm{Cr}^{3+}$ in PLGA/NMP oleosol, which enabled the repeated "charging" process by LED excitation. The LED and PersL-induced-PDT efficiently activated a tumor-sensitive HPPH for ROS generation and remarkably improved therapeutic effects. Yu et al. developed a facile "turning solid into hydrogel" strategy to make full use of PersL for high-efficient PDT [113]. The PersL-hydrogel was simply prepared by mixing 
Table 2 A summary of published works about PLNPs-based PDT

\begin{tabular}{|c|c|c|c|c|c|c|c|}
\hline PLNPS & Surface coating & Photosensitizers & Attached strategy & Loading capacity & Excitation source & Operated subject & Refs. \\
\hline $\begin{array}{l}\mathrm{Zn}_{1.25} \mathrm{Ga}_{1.5} \mathrm{Ge}_{0.25} \mathrm{O}_{4}: \mathrm{Cr}^{3+}, \\
\mathrm{Yb}^{3+}, \mathrm{Er}^{3+}\end{array}$ & Mesoporous silica & AIPCS & pore loading & $3.2 \mathrm{wt} \%$ & UV light & Cells & [109] \\
\hline Hollow $\mathrm{ZnGa}_{2} \mathrm{O}_{4}: \mathrm{Cr}^{3+}$ & BSA & Si-Pc & Pore loading & $850 \mathrm{mg} / \mathrm{g}$ & LED & Animal (iv) & [54] \\
\hline $\mathrm{Zn}_{2} \mathrm{Ga}_{2.98} \mathrm{Ge}_{0.75} \mathrm{O}_{8}: \mathrm{Cr}^{3+}{ }_{0.02} \mathrm{Bi}^{3+}{ }_{x}$ & Mesoporous silica & $\mathrm{ZnPC}$ & Pore loading & $0.346 w t \%$ & Red light & Animal (it) & {$[110]$} \\
\hline $\mathrm{ZnGa}_{2} \mathrm{O}_{4}: \mathrm{Cr}^{3+}$ & $\begin{array}{l}\text { Oleic acid and } \\
\text { hexadecanol }\end{array}$ & IR780 iodine & Wax-sealed & $33.7 \pm 2.8 \mathrm{wt} \%$ & LED & Animal (iv) & [111] \\
\hline $\mathrm{ZnGa}_{1.996} \mathrm{O}_{4}: \mathrm{Cr}^{3+}$ & PLGA/NMP oleosol & $\mathrm{HPPH}$ & - & - & LED & Animal (it) & {$[112]$} \\
\hline $\begin{array}{c}\mathrm{Zn}_{1.25} \mathrm{Ga}_{1.5} \mathrm{Ge}_{0.25} \mathrm{O}_{4}: \mathrm{Cr}^{3+}, \\
\mathrm{Yb}^{3+}, \mathrm{Er}^{3+}\end{array}$ & $\begin{array}{l}\text { Alginate- } \mathrm{Ca}^{2+} \\
\text { hydrogel }\end{array}$ & Chlorin e6 & - & - & Red light & Animal (it) & {$[11$} \\
\hline $\mathrm{Zn}_{3} \mathrm{Ga}_{2} \mathrm{GeO}_{8}: \mathrm{Cr}^{3+}$ & Silylation & Si-Pc & Covalent binding & - & $808 \mathrm{~nm}$ laser & Animal (it) & {$[11$} \\
\hline $\begin{array}{l}\mathrm{NaYF}_{4}: \mathrm{Yb}^{3+}, \mathrm{Tm}^{3+} \mathrm{SrAl}_{2} \mathrm{O}_{4}: \\
\mathrm{Eu}^{2+}, \mathrm{Dy}^{3+}\end{array}$ & $\begin{array}{l}\text { Polydimethylsi- } \\
\text { loxane }\end{array}$ & Rose Bengal & Hydrogel loading & $1.565 \mathrm{mg} / \mathrm{g}$ & $980 \mathrm{~nm}$ laser & Animal (it) & {$[115]$} \\
\hline $\mathrm{ZnS}: \mathrm{Cu}, \mathrm{Co}$ & & TBrRh123 & $\begin{array}{l}\text { Amidation cross- } \\
\text { linking }\end{array}$ & 5 wt $\%$ & X-ray & Cells & {$[116]$} \\
\hline $\mathrm{SrAl}_{2} \mathrm{O}_{4}: \mathrm{Eu}^{2+}$ & Mesoporous silica & MC540 & Pore loading & 15 wt $\%$ & X-ray & Animal (it) & {$[117]$} \\
\hline $\mathrm{LiGa}_{5} \mathrm{O}_{8}: \mathrm{Cr}^{3+}$ & Mesoporous silica & $\begin{array}{l}\text { 2,3-Naphthalocya- } \\
\text { nine }\end{array}$ & Pore loading & $2 w t \%$ & X-ray & Animal (iv) & [69] \\
\hline $\mathrm{ZnGa}_{2} \mathrm{O}_{4}: \mathrm{Cr} / \mathrm{W}$ & Silylation & $\mathrm{ZnPCS4}$ & Covalent binding & $32.25 \mu \mathrm{gg} / \mathrm{mg}$ & X-ray & Animal (iv) & [119] \\
\hline $\begin{array}{l}\text { Mesoporous } \\
\qquad \mathrm{Zn}_{3} \mathrm{Ga}_{2} \mathrm{GeO}_{8}: \mathrm{Cr}^{3+}, \mathrm{Yb}^{3+}, \mathrm{Er}^{3+}\end{array}$ & PEG modification & Si-Pc & Pore loading & 29.7 wt $\%$ & X-ray & Animal (iv) & {$[11$} \\
\hline
\end{tabular}

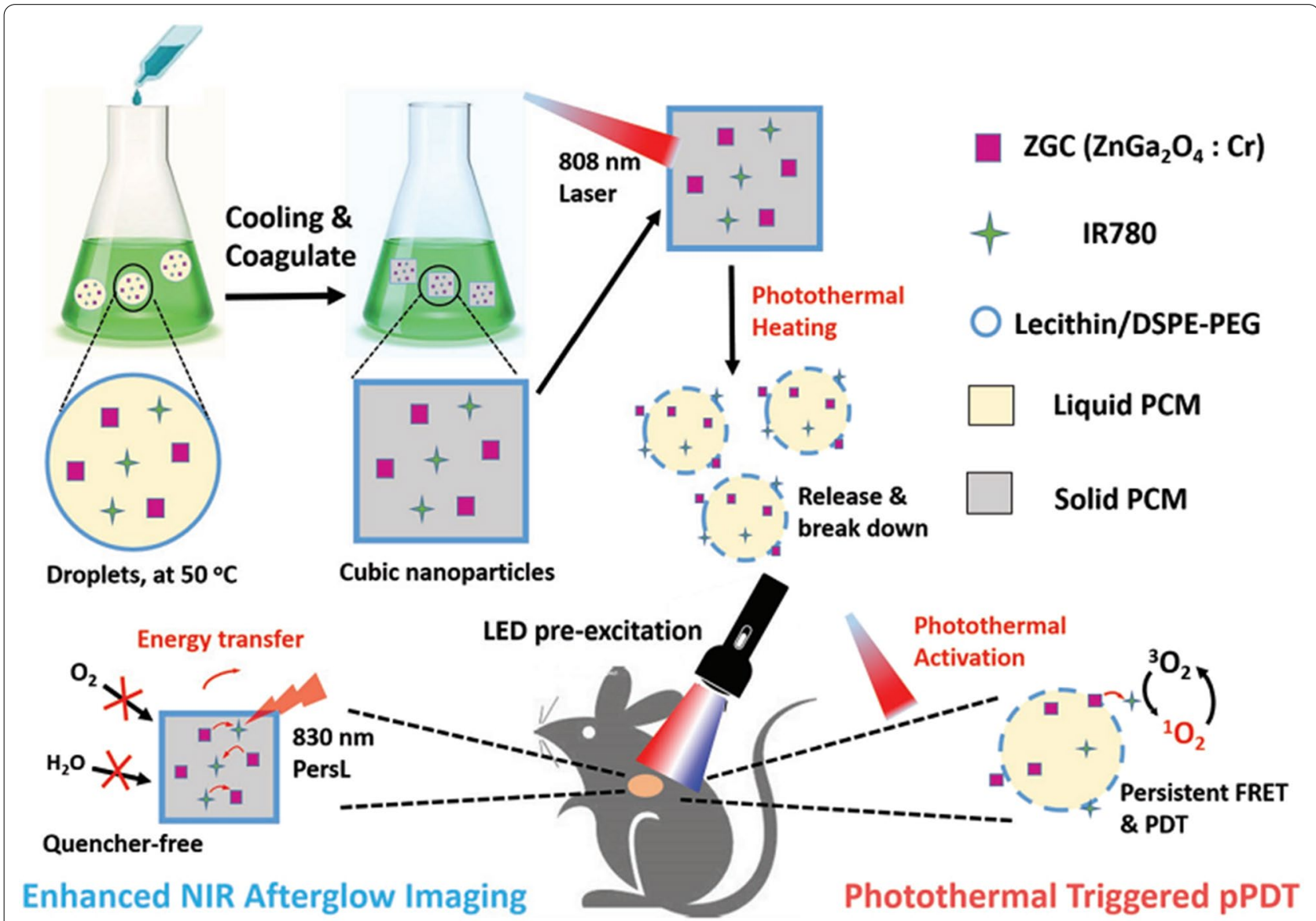

Fig. 12 A scheme of the "wax-seal" design of IR- $\mathrm{ZnGa}_{2} \mathrm{O}_{4}: \mathrm{Cr}^{3+}$ nanoplatform for enhanced PersL imaging and photothermal-triggered persistent PDT. (Reproduced with permission [111]. Copyright 2019, Wiley-VCH) 
PLNPs into a biocompatible alginate- $\mathrm{Ca}^{2+}$ hydrogel. Then the PL-hydrogel offered intact and renewable PL for continuous PDT of tumors.

To enhance the excitation depth, the longer-wavelength excitation could be the potential excitation source. Yan et al. reported the covalent coupling of Si-Pc onto $\mathrm{Zn}_{3} \mathrm{Ga}_{2} \mathrm{GeO}_{8}: \mathrm{Cr}^{3+}$ for $808 \mathrm{~nm}$ laser repeated PersL-sensitized long-term PDT of tumors [114]. The PLNPs were excited by $808 \mathrm{~nm}$ laser with $694 \mathrm{~nm}$ PersL emission for SiPc's activation. Zhang et al. reported a NIR rechargeable "optical battery" implant for irradiation-free PDT by loading $\mathrm{NaYF}_{4}: \mathrm{Yb}^{3+}, \mathrm{Tm}^{3+}, \mathrm{SrAl}_{2} \mathrm{O}_{4}: \mathrm{Eu}^{2+}, \mathrm{Dy}^{3+}$, rose bengal into biocompatible polydimethylsiloxane (PDMS) [115]. In such a system, $980 \mathrm{~nm}$ NIR laser can be firstly excited $\mathrm{NaYF}_{4}: \mathrm{Yb}^{3+}, \mathrm{Tm}^{3+}$ with $\mathrm{UV} /$ blue emission, then the activated SAO, in turn, emits green light to trigger rose Bengal for ROS generation. The implants can be repeatably charged by $5 \mathrm{~s}$ NIR light but for $30 \mathrm{~min}$ effective PDT time, which effectively generate ROS for tumor inhibition.

Inspired by the superior penetration depth of X-ray for the activation of PLNPs, Solberg et al. first employed PLNPs as the photon transducer to achieve X-rayinduced PDT [116]. He used Tetrabromorhodamine-123 (TBrRh123) to conjugate on $\mathrm{ZnS}: \mathrm{Cu}, \mathrm{Co}$ PLNPs, where the emission spectrum of $\mathrm{ZnS}: \mathrm{Cu}, \mathrm{Co}$ was overlapped with the absorption spectrum of TBrRh123. After the $\mathrm{X}$-ray excitation, the nanoplatform continuously generated ROS for human prostate cancer cells killing. Later, Xie et al. reported Merocyanine540 (MC540)-loaded silica-coated-SrAl $\mathrm{O}_{4}: \mathrm{Eu}^{2+}$ (SAO) nanoplatform for in vivo PDT, where the SAO could effectively convert $\mathrm{X}$-rays photons to visible photons for activating MC540 to generate ${ }^{1} \mathrm{O}_{2}$ and suppress tumor growth [117]. However, this therapeutic effect was achieved with intratumorally injected nanoparticles on subcutaneous tumor models. Then Xie et al. later reported 2,3-naphthalocyanine and $\mathrm{LiGa}_{5} \mathrm{O}_{8}: \mathrm{Cr}^{3+}$ co-loaded mesoporous silica nanoparticles (NC-LGO:Cr@mSiO ${ }_{2}$ ) for PDT of H1299 orthotopic lung cancer [69]. The nanoformulation was passively accumulated to lung tumors. Upon X-ray's irradiation, the tumors were obtained efficient inhibition. Furthermore, Chen et al. reported another nanoplatform by loading silicon phthalocyanine into mesoporous $\mathrm{Zn}_{3} \mathrm{Ga}_{2} \mathrm{GeO}_{8}: \mathrm{Cr}^{3+}, \mathrm{Yb}^{3+}, \mathrm{Er}^{3+}$ (mZGGOs) for X-rayinduced PersL imaging and effective suppression of orthotopic hepatic tumors [118]. Due to the safety concern of high-dose X-ray, Yang et al. developed a low-dose $\mathrm{X}$-ray-activated PLNP-mediated PDT nanoplatform for renewable cancer treatment (Fig. 13a) [119]. The synthesized ZGO:Cr/W exhibited stronger PersL and excellent $\mathrm{X}$-ray absorption, allowing for more photons to activate $\mathrm{Zn}$ (II) phthalocyanine tetrasulfonic acid ( $\mathrm{ZnPcS4}$ ).
Besides, 0.18 Gy X-ray's irradiation for this nanoplatform also produced enough PDT effect for the treatment of deep-seated tumor (Fig. 13b,c).

\section{PLNPs based chemotherapy}

Nanocarriers can enable the loading of multiple chemotherapeutic drugs while enhancing efficient drug delivery to tumors. Currently, PLNPs with different nanostructure have been explored as nanocarriers for chemodrugs loading and delivery. Several design strategies have been proposed on PLNPs, mainly resting on the physical absorption of porous nanostructure (Table 3). Firstly, PLNPs with their own mesoporous structure have attracted considerable attention for drug delivery because of their high cavity volumes and specific surface area. For example, Zhang et al. designed hollow $\mathrm{ZnGa}_{2} \mathrm{O}_{4}: \mathrm{Cr}^{3+}$ with high doxorubicin (DOX) loading for PersL imaging-guided chemotherapy [54]. Lv et al. developed raspberry-like mesoporous $\mathrm{Zn}_{1.07} \mathrm{Ga}_{2.34} \mathrm{Si}_{0.98} \mathrm{O}_{6.56}: \mathrm{Cr}_{0.01}$ nanostructures for enhanced PersL imaging and chemotherapy of tumor [66]. These two mesoporous PLNPs nanostructures both had excellent high drug loading efficiency, and the authors utilized BSA to modify the structures to improve biocompatibility and colloidal stability. Besides, mesoporous silica shells coating on PLNPs can be another strategy for drug loading. Zhang et al. employed mesoporous silica nanospheres (MSNs) both as morphology-controlling templates and as drug carriers to design porous PLNPs [32, 34]. Hsiao et al. also used MSNs as the templates to synthesize PLNPs which were loaded with afatinib (AFT) chemodrugs and attached with specific targeting aptamer (MAGE-A3) (Fig. 14a) [120]. Then they used these PLNPs for in situ inhabitation of lung adenocarcinoma progression. PersL imaging of orthotopic lung cancer models and isolated lung and $H \& E$ staining all confirm the therapeutic effect (Fig. 14b-d). Wang et al. firstly did the mesoporous silica-coated on the PNLPs, then extrude red blood cells membrane vesicles or Lactobacillus reuteri biofilm on the PLNPs@SiO ${ }_{2}$ surface to endow these nanocarriers with the ability to evade macrophage phagocytosis and systemic metabolism [70, 73]. Yan et al. constructed MSNs coated PersL nanoplatform (pHLIP-SS-GFLG-MSPLNPs @DOX), which had the properties of cathepsin B/glutathione dual-responsive drug release [121]. Own to the specific-response in the tumor microenvironment, the nanoplatform effectively released the DOX for cell killing and tumor inhibition. Liposomes, as the widely used nanocarriers, have the advantages of good biocompatibility and biodegradability. Thus Yan et al. employed liposome coated PLNPs (PLNPs-Liposome) for DOX loading and PersL imaging-guided chemotherapy, where these nanoformulations exhibited high DOX loading 


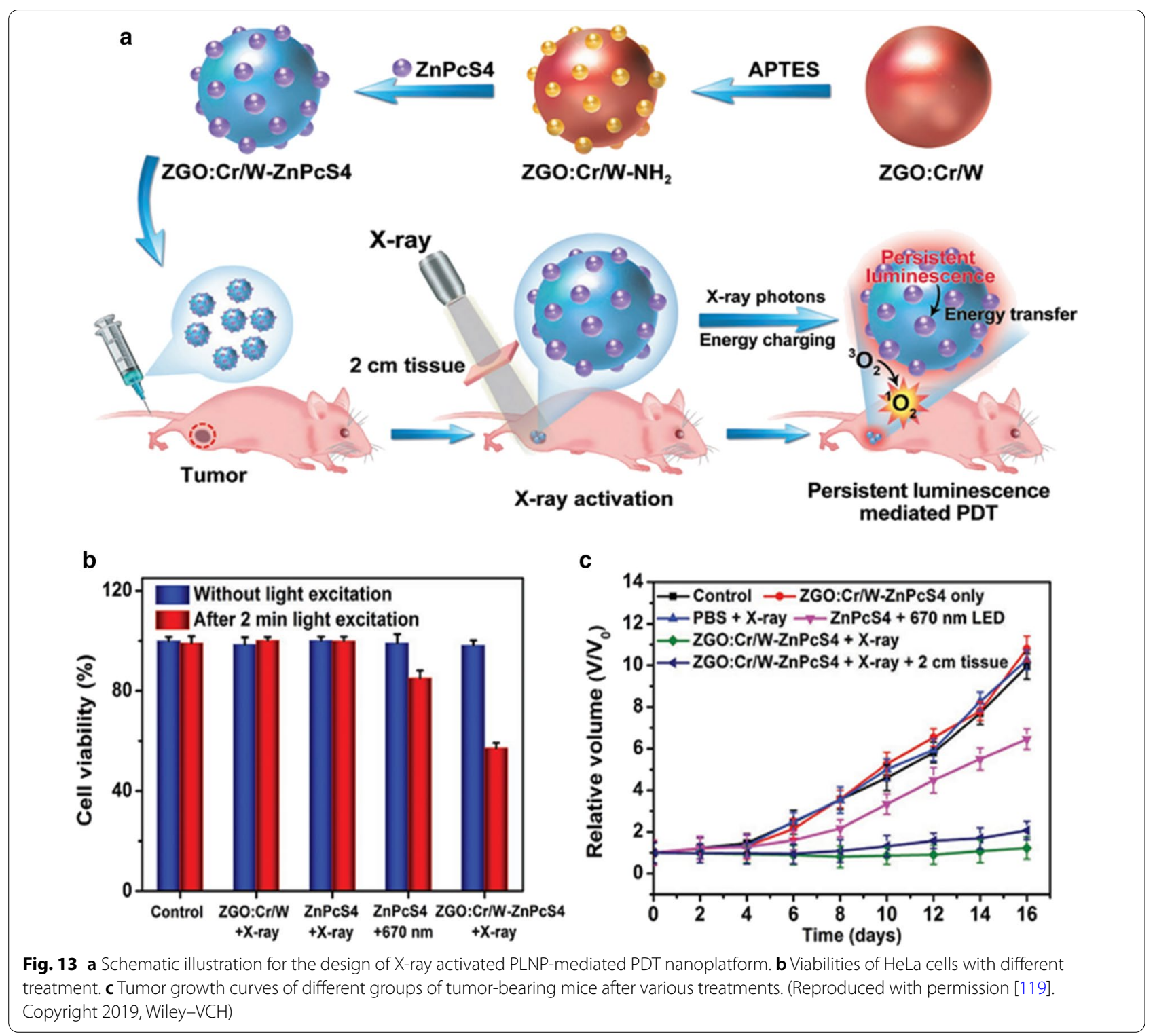

efficiency $(69.2 \pm 2.8 \%)$ and remarkable therapeutic capability for tumors [122]. In addition, Zeolitici imidazolate framework-8 (ZIF-8) has been commonly applied for $\mathrm{pH}$-sensitive drug delivery due to the superior drug loading capacity and good biocompatibility [123]. Hence, PLNPs@ZIF-8 core-shell nanostructures were constructed for drug delivery, which achieved high DOX loading and tumor-specific drug release [124, 125].

\section{PLNPs based gene therapy}

Gene therapy has demonstrated high specificity, efficacy, and relatively few side effects in rehabilitation after surgical resection [127]. Han et al. designed a LED-responsive gene delivery system for localized gene therapy, where Gold nanorods and hTERT siRNA were col-loaded on $\mathrm{ZnGa}_{2} \mathrm{O}_{4}: \mathrm{Cr}^{3+}$ nanofibers. The gold nanorods absorbed the energy from LED radiated- $\mathrm{ZnGa}_{2} \mathrm{O}_{4}: \mathrm{Cr}^{3+}$ nanofibers to generate a mild photothermal effect and in turn induced the release of siRNA, which amplified the gene silencing effect [128]. Yan et al. constructed cell-penetrating TAT peptide and eGFP-TRAIL decorated PLNPs nanocomposite (PLNPs-PPT/TRAIL) for mesenchymal stem cells (MSC) tracking and effective therapy of glioblastoma (Fig. 15) [129]. The dual-functional nanocomposite not only enabled efficient targeting of MSC to induce therapeutic TRAIL ligand but also utilized afterglow to track the migration of MSC shifts over time. 
Table 3 A summary of published works about PLNPs-based chemotherapy

\begin{tabular}{|c|c|c|c|c|c|}
\hline PLNPS & Surface coating & Loaded drug & Loading capacity & Operated subject & Refs. \\
\hline Hollow $\mathrm{ZnGa}_{2} \mathrm{O}_{4}: \mathrm{Cr}$ & BSA & DOX & $181 \mathrm{mg} / \mathrm{g}$ & Animal (iv) & {$[54]$} \\
\hline Mesoporous $\mathrm{Zn}_{1.07} \mathrm{Ga}_{2.34} \mathrm{Si}_{0.98} \mathrm{O}_{6.56}: \mathrm{Cr}_{0.01}$ & BSA & DOX & 62 wt \% & Animal (iv) & {$[66]$} \\
\hline $\mathrm{Zn}_{1.1} \mathrm{Ga}_{1.8} \mathrm{Ge}_{0.1} \mathrm{O}_{4}: \mathrm{Cr}^{3+}$ & Mesoporous silica & DOX & 4.5 wt $\%$ & cells & {$[32]$} \\
\hline $\mathrm{Gd}_{3} \mathrm{Ga}_{5} \mathrm{O}_{12}: \mathrm{Cr}^{3+}, \mathrm{Nd}^{3+}$ & Mesoporous Silica & DOX & $8.5 \mathrm{wt} \%$ & Animal (it) & {$[34]$} \\
\hline $\mathrm{ZnGa}_{2} \mathrm{O}_{4}: \mathrm{Cr}^{3+}, \mathrm{Sn}^{4+}$ & Mesoporous Silica & Paclitaxel & $187 \mathrm{mg} / \mathrm{g}$ & cells & [126] \\
\hline $\mathrm{ZnGa}_{2} \mathrm{O}_{4}: \mathrm{Cr}^{3+}, \mathrm{Sn}^{4+}$ & Mesoporous Silica & Afatinib & $15 w t \%$ & Animal (iv) & [120] \\
\hline $\mathrm{Zn}_{1.25} \mathrm{Ga}_{1.5} \mathrm{Ge}_{0.25} \mathrm{O}_{4}: \mathrm{Cr}^{3+}, \mathrm{Yb}^{3+}, \mathrm{Er}^{3+}$ & Mesoporous Silica, RBC vesicles & DOX & $7.1 \pm 0.3 w t \%$ & Animal (iv) & {$[70]$} \\
\hline $\mathrm{Zn}_{1.25} \mathrm{Ga}_{1.5} \mathrm{Ge}_{0.25} \mathrm{O}_{4}: \mathrm{Cr}^{3+}, \mathrm{Yb}^{3+}, \mathrm{Er}^{3+}$ & $\begin{array}{l}\text { Mesoporous Silica, Lactobacillus } \\
\text { reuteri biofilm }\end{array}$ & Fluorouracil & $8.5 \mathrm{wt} \%$ & Animal (it) & {$[73]$} \\
\hline $\mathrm{Zn}_{1.1} \mathrm{Ga}_{1.8} \mathrm{Ge}_{0.1} \mathrm{O}_{4}: \mathrm{Cr}^{3+}, \mathrm{Eu}^{3+}$ & Mesoporous silica & DOX & $105.9 \mathrm{mg} / \mathrm{g}$ & Animal (iv) & [121] \\
\hline $\mathrm{Zn}_{1.1} \mathrm{Ga}_{1.8} \mathrm{Ge}_{0.1} \mathrm{O}_{4}: \mathrm{Cr}^{3+}$ & Liposome & Paclitaxel & $69.2 \pm 2.8$ wt $\%$ & Animal (iv) & [122] \\
\hline $\mathrm{Zn}_{\mathrm{x}} \mathrm{Ga}_{\mathrm{y}} \mathrm{Ge}_{\mathrm{z}} \mathrm{O}_{4}: \mathrm{Cr}^{3+}$ & ZIF-8 & DOX & $93.2 \mathrm{wt} \%$ & Animal (it) & [125] \\
\hline $\mathrm{ZnGa}_{2} \mathrm{O}_{4}: \mathrm{Cr}^{3+}$ & ZIF-8 & DOX & $90 w t \%$ & Animal (iv) & [124] \\
\hline
\end{tabular}

\section{PLNPs based combined therapy}

Combined therapy can overcome the insufficient therapeutic effect of single therapy [9]. Therefore, Yan et al. developed a biomimetic PersL nanoplatform for metastasis tracking and chemophotodynamic therapy. The nanoplatform (DSPLNPs@hSiO $@$ @CCM) were constructed on cancer cell membrane (CCM) and hollow silica multilayer coated PLNPs, which afforded the high loading capacity of $\mathrm{Si}-\mathrm{Pc}$ and DOX in the nanoplatform. The reactivatable PersL from PLNPs not only provided long-term PersL imaging of metastases, but also was as an internal light source for $\mathrm{Si}-\mathrm{Pc}$ activation, which enhanced the intracellular DOX release and achieved controllable combined chemophotodynamic therapy of metastases. Zhang et al. designed a PersL nanoplatform (PHFI) which co-doped human serum albumin (IR780 iodien and $\mathrm{Fe}^{3+}$ ) was coated on PLNPs (Fig. 16a) [130]. The PHFI were used for MR/PA/PersL imaging of tumors (Fig. 16b). Meanwhile, PHFI exhibited the Fenton-like chemodynamic therapy as well as phototherapy, which effectively achieved efficient tumor inhibition in vitro and in vivo (Fig. 16c,d). Wang et al. constructed cancer cell macrophage membrane-camoouflaged PLNPs-based nanoplatforms for combined PTT and chemotherapy of colorectal cancer [72]. The nanoplatforms were firstly coated PLNPs with mesoporous silica, then loaded with photothermal agent (IR825) and chemodrug (irinotecan), and lastly encapsulated into cell macrophage membrane. With the excellent tumor homologous adhesion and combined therapy effect, the colorectal tumors were obtained good inhibition. Sun et al. developed ${ }^{131}$ I labeled $\mathrm{ZnPc}(\mathrm{COOH})_{4}$ conjugated $\mathrm{ZnGa}_{2} \mathrm{O}_{4}: \mathrm{Cr}^{3+}$ nanoplatform $\left({ }^{131} \mathrm{I}-\mathrm{ZGCs}-\mathrm{ZnPcC} 4\right)$ for both radiation-induced PDT and radionuclide therapy (RT) [131]. ${ }^{131}$ I as the therapeutic radionuclides not only produced the gamma-ray for RT but also served as internal excitation source to activate $\mathrm{ZnGa}_{2} \mathrm{O}_{4}: \mathrm{Cr}^{3+}$ with long-lasting luminescence for further continuously generating PDT from $\mathrm{ZnPc}(\mathrm{COOH})_{4}$. Due to these self-activated therapies, ${ }^{131} \mathrm{I}$-ZGCs-ZnPcC4 could highly do good for deep tumor therapy. Recently, Yan et al. reported the $\mathrm{pH}$-responsive cyanine conjugated PLNPs for PersL imaging of tumor and PTT/PDT combined therapy [132]. The conjugated cyanine offered the photothermal and photodynamic properties for tumor treatment.

\section{Conclusion and outlook}

We summarized the current research progress of PLNPs in the synthesis, surface modification, and their applications in bioimaging and cancer therapy. Although great processes are made in the biomedical application of PLNPs, there remain some issues that deserve further studies.

(1) Although many advances have been made in the synthesis of PLNPs, the morphological regulation of PLNPs still has some problems. With the development of PLNPs in biomedical applications, more advanced synthetic methods are needed to precisely control the morphology, particle size, surface properties, PersL intensity, and PersL time of PLNPs.

(2) The excitation light source is an important factor affecting the biomedical application of PLNPs. Since the PersL time for pre-excitation by UV lamps is not sufficient to support the tumor accumulation of PLNPs, future studies will focus on NIR light, X-ray, and radionuclides as the light sources for PLNPs' excitation. Meanwhile, the emission of PLNPs in the NIR I or NIR II range can achieve better tissue transmittance. As PLNPs with NIR II 


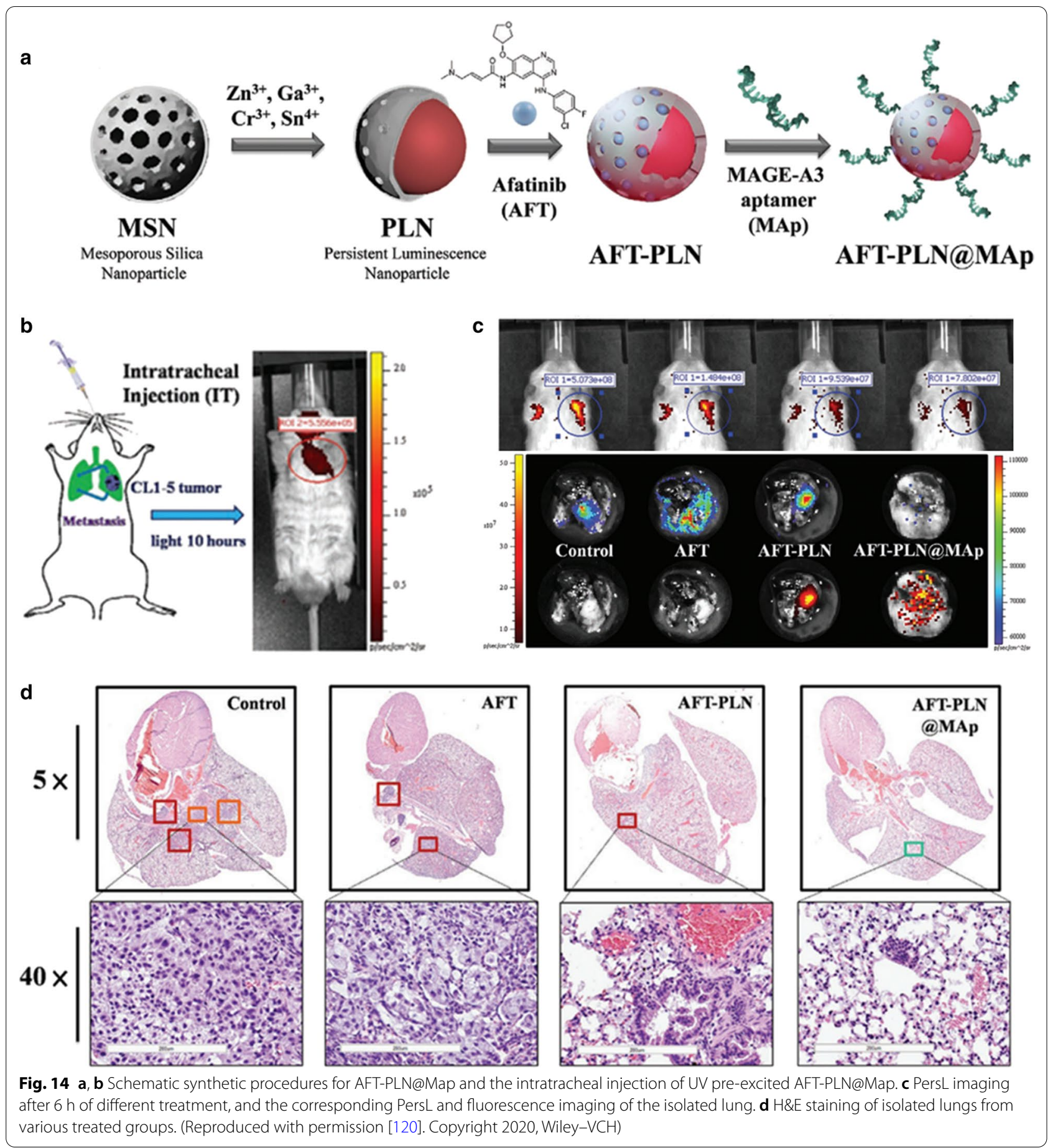

emission have been seldom reported for bioimaging, thus, the development of PLNPs with excellent NIR II PersL will be one of the future research hotspots.

(3) Although PLNPs can provide PersL with high sensitivity for disease diagnosis, it cannot provide all the information needed in the process of disease diag- nosis and treatment. Therefore, PLNPs with multimodal imaging properties are paid attention for cancer diagnosis.

(4) PLNPs as smart drug delivery systems can be used for PTT, PDT, chemotherpay, gene therapy, and combined therapy. The main challenge so far is how to construct PLNPs nanoplatform with high-effec- 

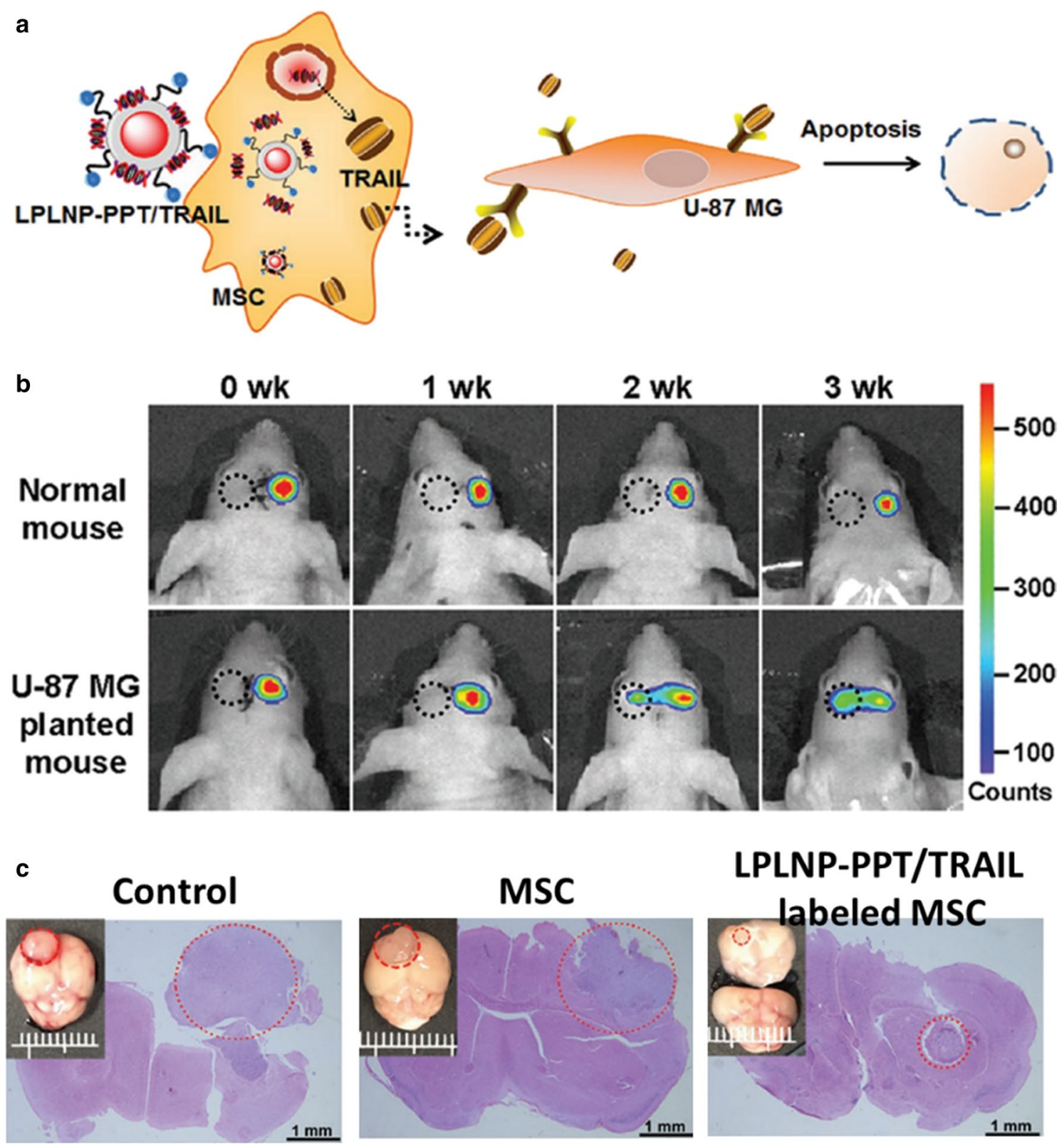
labeled MSC

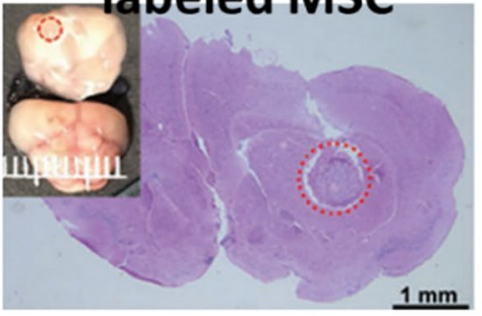

Fig. 15 a A scheme for LPLNP-PPT/TRAIL based MSC tracking and gene therapy. b In vivo migration study of LPLNP-PPT labeled MSC. c Histology analysis of orthotopic brain tumor with different treatments. (Reproduced with permission [129]. Copyright 2020, Wiley-VCH)

tive loading, adequate protection of therapeutic payloads during circulation, target-specific delivery, sufficient cellular internalization.

(5) As a new type of fluorescent nanomaterial, PLNPs are currently used in tumor diagnosis and treatment. Compared with other fluorescent nanoprobes, such as quantum dots and upconversion nanoparticles, their application scenarios in the biomedical field are relatively limited. In the future, more applications of PLNPs in the biomedical field will be developed, such as in vitro diagnostics, cell imaging, and antibacterial disinfection, etc.

(6) The biosafety studies of PLNPs, as a novel bioimaging material, have also been the focus of attention of researchers. Although researchers have investigated the biotoxicity of PLNPs at multiple levels, including cellular and animal, and have achieved many research results, however, the biosafety studies of PLNPs are still in their infancy. In the future, more attention will be paid to deeper biotoxicity stud- 

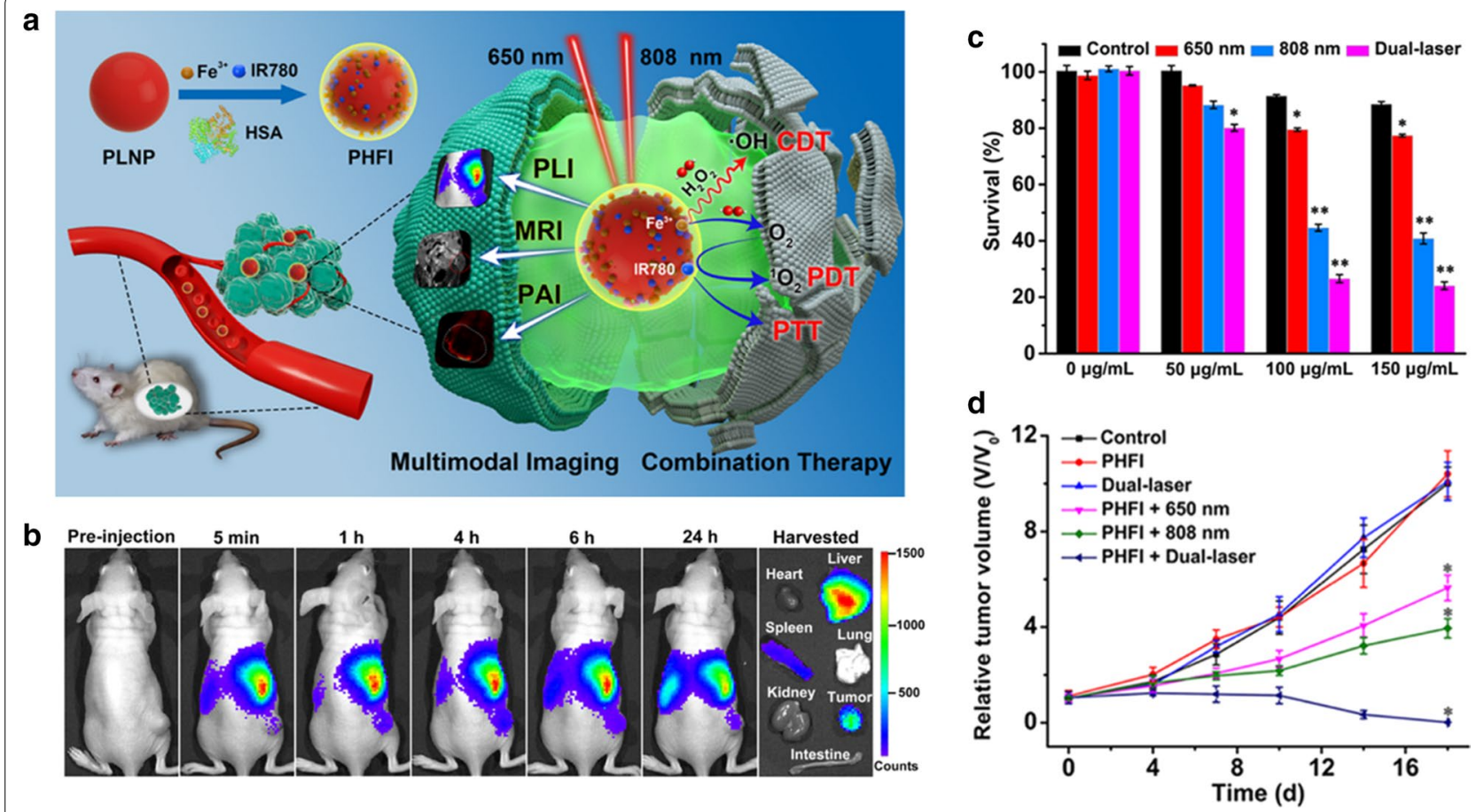

Fig. 16 a Schematic representation of multimodal imaging and combination therapy. $\mathbf{b}$ In vivo PersL imaging of 4T1 tumor-bearing mice. $\mathbf{c}$ In vitro concentration-dependent cell viabilities of PHFI treated 4T1 cells with different laser irradiations. $\mathbf{d}$ Tumor-growth profiles of tumor-bearing mice with different treatment. (Reproduced with permission [130]. Copyright 2020, American Chemical Society)

ies, such as the change of protein and gene at the molecular biology level, the chronic exposure toxicity, migration distribution, and transformation of PLNPs at the animal level.

\section{Acknowledgements}

Not applicable.

\section{Authors'contributions}

$\mathrm{NL}$ and XC have collected literature and wrote the manuscript. XS, XS, and JS edited the manuscript. All authors read and approved the final manuscript.

\section{Funding}

This study was supported by National Natural Science Foundation of China $(61705228,81971738,81571743)$, the National Key Research and Development Program of China (2016YFA0203600), and the Project Program of State Key Laboratory of Natural Medicines, China Pharmaceutical University (SKLNMZZRC05).

\section{Availability of data and materials}

Not applicable.

\section{Declarations}

Ethics approval and consent to participate Not applicable.

\section{Consent of publication}

Not applicable.

\section{Competing interests}

The authors declare that they have no competing interests.

\section{Author details}

${ }^{1}$ Xiamen Cardiovascular Hospital, Xiamen University, Xiamen 361015, China.

${ }^{2}$ State Key Laboratory of Natural Medicines, Key Laboratory of Drug Quality Control and Pharmacovigilance, Department of Pharmaceutical Analysis, China Pharmaceutical University, Nanjing 210009, China. ${ }^{3}$ Department of Chemistry, Technical University of Munich, 85747 Garching, Germany. ${ }^{4}$ Medizinische Klinik Und Poliklinik IV, Ludwig-Maximilians-Universität München, 80336 Munich, Germany. ${ }^{5}$ Key Laboratory of Design and Assembly of Functional Nanostructures, Fujian Institute of Research On the Structure of Matter, Chinese Academy of Sciences, Fuzhou 350002, China. ${ }^{6}$ Department of Translational Medicine, Xiamen Institute of Rare Earth Materials, Chinese Academy of Sciences, Xiamen 361021, China.

Received: 12 February 2021 Accepted: 9 April 2021 Published online: 20 April 2021

\section{References}

1. Lozano R, Naghavi M, Foreman K, Lim S, Shibuya K, Aboyans V, Abraham J, Adair T, Aggarwal R, Ahn S, et al. Global and regional mortality from 235 causes of death for 20 age groups in 1990 and 2010: a systematic analysis for the Global Burden of Disease Study 2010. Lancet. 2012;380:2095-128.

2. Shi J, Kantoff PW, Wooster R, Farokhzad OC. Cancer nanomedicine: progress, challenges and opportunities. Nat Rev Cancer. 2017;17:20-37.

3. Park S-M, Aalipour A, Vermesh O, Yu JH, Gambhir SS. Towards clinically translatable in vivo nanodiagnostics. Nat Rev Mater. 2017;2:17014. 
4. Dai Y, Xu C, Sun X, Chen X. Nanoparticle design strategies for enhanced anticancer therapy by exploiting the tumour microenvironment. Chem Soc Rev. 2017:46:3830-52.

5. Shrestha B, Tang L, Romero G. Nanoparticles-mediated combination therapies for cancer treatment. Adv Ther. 2019;2:1900076.

6. Attia MF, Anton N, Wallyn J, Omran Z, Vandamme TF. An overview of active and passive targeting strategies to improve the nanocarriers efficiency to tumour sites. J Pharm Pharmacol. 2019;71:1185-98.

7. Lecuyer T, Teston E, Ramirez-Garcia G, Maldiney T, Viana B, Seguin J, Mignet N, Scherman D, Richard C. Chemically engineered persistent luminescence nanoprobes for bioimaging. Theranostics. 2016;6:2488-524.

8. Holsa J. Persistent luminescence beats the afterglow: 400 years of persistent luminescence. Electrochem Soc Interface. 2009;18:42.

9. Li Y, Gecevicius M, Qiu J. Long persistent phosphors-from fundamentals to applications. Chem Soc Rev. 2016:45:2090-136.

10. Xu J, Tanabe S. Persistent luminescence instead of phosphorescence: history, mechanism, and perspective. J Lumin. 2019;205:581-620.

11. Choi HS, Liu W, Misra P, Tanaka E, Zimmer JP, Itty Ipe B, Bawendi MG, Frangioni JV. Renal clearance of quantum dots. Nat Biotechnol. 2007:25:1165-70.

12. Michalet $X$, Pinaud FF, Bentolila LA, Tsay JM, Doose S, Li JJ, Sundaresan G, Wu A, Gambhir S, Weiss S. Quantum dots for live cells, in vivo imaging, and diagnostics. Science. 2005;307:538-44.

13. Rao L, Bu L-L, Cai B, Xu J-H, Li A, Zhang W-F, Sun Z-J, Guo S-S, Liu W, Wang T-H, Zhao X-Z. Cancer cell membrane-coated upconversion nanoprobes for highly specific tumor imaging. Adv Mater. 2016;28:3460-6.

14. Chien Y-H, Chou Y-L, Wang S-W, Hung S-T, Liau M-C, Chao Y-J, Su C-H, Yeh C-S. Near-infrared light photocontrolled targeting, bioimaging, and chemotherapy with caged upconversion nanoparticles in vitro and in vivo. ACS Nano. 2013;7:8516-28.

15. Lee S, Lim W, Ryu HW, Jo D, Min JJ, Kim HS, Hyun H. ZW800-1 for assessment of blood-brain barrier disruption in a photothrombotic stroke model. Int J Med Sci. 2017;14:1430-5.

16. Carr JA, Franke D, Caram JR, Perkinson CF, Saif M, Askoxylakis V, Datta M, Fukumura D, Jain RK, Bawendi MG, Bruns OT. Shortwave infrared fluorescence imaging with the clinically approved near-infrared dye indocyanine green. Proc Natl Acad Sci. 2018;115:4465-70.

17. Liu J, Lecuyer T, Seguin J, Mignet N, Scherman D, Viana B, Richard C. Imaging and therapeutic applications of persistent luminescence nanomaterials. Adv Drug Deliv Rev. 2019;138:193-210.

18. Zhou Z, Li Y, Peng M. Near-infrared persistent phosphors: synthesis, design, and applications. Chem Eng J. 2020;399:125688.

19. Wu S, Li Y, Ding W, Xu L, Ma Y, Zhang L. Recent advances of persistent luminescence nanoparticles in bioapplications. Nano-Micro Lett. 2020;12:1-26

20. Sun SK, Wang HF, Yan XP. Engineering persistent luminescence nanoparticles for biological applications: from biosensing/bioimaging to theranostics. Acc Chem Res. 2018;51:1131-43.

21. Wang J, Ma Q, Wang Y, Shen H, Yuan Q. Recent progress in biomedical applications of persistent luminescence nanoparticles. Nanoscale. 2017;9:6204-18.

22. Lin Q, Li Z, Yuan Q. Recent advances in autofluorescence-free biosensing and bioimaging based on persistent luminescence nanoparticles. Chin Chem Lett. 2019;30:1547-56.

23. Liu F, Liang Y, Chen Y, Pan Z. Divalent Nickel-activated gallate-based persistent phosphors in the short-wave infrared. Adv Opt Mater. 2016;4:562-6.

24. Li Y, Zhou S, Li Y, Sharafudeen K, Ma Z, Dong G, Peng M, Qiu J. Long persistent and photo-stimulated luminescence in $\mathrm{Cr}^{3+}$-doped $\mathrm{Zn}-\mathrm{Ga}-$ $\mathrm{Sn}-\mathrm{O}$ phosphors for deep and reproducible tissue imaging. J Mater Chem C. 2014;2:2657-63.

25. Abdukayum A, Chen JT, Zhao Q, Yan XP. Functional near infrared-emitting $\mathrm{Cr}^{3+} / \mathrm{Pr}^{3+}$ co-doped zinc gallogermanate persistent luminescent nanoparticles with superlong afterglow for in vivo targeted bioimaging. J Am Chem Soc. 2013;135:14125-33.

26. Pan Z, Lu Y-Y, Liu F. Sunlight-activated long-persistent luminescence in the near-infrared from $\mathrm{Cr}^{3+}$-doped zinc gallogermanates. Nat Mater. 2011;11:58-63.

27. Liu F, Liang Y, Pan ZW. Detection of up-converted persistent luminescence in the near infrared emitted by the $\mathrm{Zn}_{3} \mathrm{Ga}_{2} \mathrm{GeO}_{8}: \mathrm{Cr}^{3+}, \mathrm{Yb}^{3+}, \mathrm{Er}^{3+}$ phosphor. Phys Rev Lett. 2014;113:177401.
28. Liu N, Shi J, Wang Q, Guo J, Hou Z, Su X, Zhang H, Sun X. In Vivo repeatedly activated persistent luminescence nanoparticles by radiopharmaceuticals for long-lasting tumor optical imaging. Small. 2020;16:2001494.

29. Ferreira CA, Ni D, Rosenkrans ZT, Cai W. Radionuclide-activated nanomaterials and their biomedical applications. Angew Chem Int Ed. 2019:58:13232-52.

30. Marion JB. 21 —radiation—effects and uses. In: Marion JB, editor. Physics in the modern world. 2nd ed. New York: Academic Press; 1981. p. 603-31.

31. De Chermont QLM, Chanéac C, Seguin J, Pellé F, Maîtrejean S, Jolivet J-P, Gourier D, Bessodes M, Scherman D. Nanoprobes with nearinfrared persistent luminescence for in vivo imaging. Proc Natl Acad Sci. 2007;104:9266-71.

32. Shi J, Sun X, Li J, Man H, Shen J, Yu Y, Zhang H. Multifunctional near infrared-emitting long-persistence luminescent nanoprobes for drug delivery and targeted tumor imaging. Biomaterials. 2015;37:260-70.

33. Zhan-Jun L, Hong-Wu Z, Meng S, Jiang-Shan S, Hai-Xia F. A facile and effective method to prepare long-persistent phosphorescent nanospheres and its potential application for in vivo imaging. J Mater Chem. 2012;22:24713-20.

34. Shi J, Sun X, Zheng S, Li J, Fu X, Zhang H. A new near-infrared persistent luminescence nanoparticle as a multifunctional nanoplatform for multimodal imaging and cancer therapy. Biomaterials. 2018;152:15-23.

35. Li Z, Zhang Y, Wu X, Huang L, Li D, Fan W, Han G. Direct aqueousphase synthesis of sub-10 nm "luminous pearls" with enhanced in vivo renewable near-infrared persistent luminescence. J Am Chem Soc. 2015;137:5304-7.

36. Shi JP, Sun X, Zhu JF, Li JL, Zhang H. One-step synthesis of aminofunctionalized ultrasmall near infrared-emitting persistent luminescent nanoparticles for in vitro and in vivo bioimaging. Nanoscale. 2016;8:9798-804

37. Wang J, Ma Q, Hu X-X, Liu H, Zheng W, Chen X, Yuan Q, Tan W. Autofluorescence-free targeted tumor imaging based on luminous nanoparticles with composition-dependent size and persistent luminescence. ACS Nano. 2017;11:8010-7.

38. Maldiney T, Bessière A, Seguin J, Teston E, Sharma SK, Viana B, Bos AJ, Dorenbos $P$, Bessodes M, Gourier D. The in vivo activation of persistent nanophosphors for optical imaging of vascularization, tumours and grafted cells. Nat Mater. 2014;13:418-26.

39. Li YJ, Yan XP. Synthesis of functionalized triple-doped zinc gallogermanate nanoparticles with superlong near-infrared persistent luminescence for long-term orally administrated bioimaging. Nanoscale. 2016;8:14965-70.

40. Zou R, Huang JJ, Shi JP, Huang L, Zhang XJ, Wong KL, Zhang HW, Jin DY, Wang J, Su Q. Silica shell-assisted synthetic route for monodisperse persistent nanophosphors with enhanced in vivo recharged near-infrared persistent luminescence. Nano Res. 2017;10:2070-82.

41. Maldiney T, Lecointre A, Viana B, Bessiere A, Bessodes M, Gourier D, Richard C, Scherman D. Controlling electron trap depth to enhance optical properties of persistent luminescence nanoparticles for in vivo imaging. J Am Chem Soc. 2011;133:11810-5.

42. Zhang L, Lei JP, Liu JT, Ma FJ, Ju HX. Persistent luminescence nanoprobe for biosensing and lifetime imaging of cell apoptosis via time-resolved fluorescence resonance energy transfer. Biomaterials. 2015;67:323-34.

43. Wu B-Y, Wang H-F, Chen J-T, Yan X-P. Fluorescence resonance energy transfer inhibition assay for a-fetoprotein excreted during cancer cell growth using functionalized persistent luminescence nanoparticles. J Am Chem Soc. 2011;133:686-8.

44. Li N, Li YH, Han YY, Pan W, Zhang TT, Tang B. A highly selective and instantaneous nanoprobe for detection and imaging of ascorbic acid in living cells and in vivo. Anal Chem. 2014:86:3924-30.

45. Chuang YJ, Zhen ZP, Zhang F, Liu F, Mishra JP, Tang W, Chen HM, Huang $X \mathrm{~L}$, Wang $\mathrm{LC}$, Chen $X Y$, et al. Photostimulable near-infrared persistent luminescent nanoprobes for ultrasensitive and longitudinal deep-tissue bio-imaging. Theranostics. 2014;4:1112-22.

46. Fu XY, Liu CL, Shi JP, Man HZ, Xu J, Zhang HW. Long persistent near infrared luminescence nanoprobes $\mathrm{LiGa}_{5} \mathrm{O}_{8}: \mathrm{Cr}^{3+}-\mathrm{PEG}-\mathrm{OCH}_{3}$ for in vivo imaging. Opt Mater. 2014;36:1792-7. 
47. Sun X, Shi JP, Zheng SH, Li JL, Wang SG, Zhang HW. Visualization of inflammation in a mouse model based on near-infrared persistent luminescence nanoparticles. J Lumin. 2018;204:520-7.

48. Li Z, Zhang H, Fu H. Facile synthesis and morphology control of $\mathrm{Zn}_{2} \mathrm{SiO}_{4}$ : Mn nanophosphors using mesoporous silica nanoparticles as templates. J Lumin. 2013;135:79-83.

49. Li ZJ, Shi JP, Zhang HW, Sun M. Highly controllable synthesis of nearinfrared persistent luminescence $\mathrm{SiO}_{2} / \mathrm{CaMgSi}_{2} \mathrm{O}_{6}$ composite nanospheres for imaging in vivo. Opt Expr. 2014;22:10509-18.

50. Li ZJ, Zhang YJ, Zhang HW, Fu HX. Long-lasting phosphorescence functionalization of mesoporous silica nanospheres by $\mathrm{CaTiO}_{3}: \mathrm{Pr}^{3+}$ for drug delivery. Microporous Mesoporous Mater. 2013;176:48-54.

51. Shi JP, Fu HX, Sun X, Shen JS, Zhang HW. Magnetic, long persistent luminescent and mesoporous nanoparticles as trackable transport drug carriers. J Mater Chem B. 2015;3:635-41

52. Shi JP, Sun M, Sun X, Zhang HW. Near-infrared persistent luminescence hollow mesoporous nanospheres for drug delivery and in vivo renewable imaging. J Mater Chem B. 2016;4:7845-51.

53. Zou R, Gong SM, Shi JP, Jiao J, Wong KL, Zhang HW, Wang J, Su Q. Magnetic-NIR persistent luminescent dual-modal ZGOCS@MSNs@ $\mathrm{Gd}_{2} \mathrm{O}_{3}$ core-shell nanoprobes for in vivo imaging. Chem Mater. 2017;29:3938-46.

54. Wang J, Li JL, Yu JN, Zhang HW, Zhang BB. Large hollow cavity luminous nanoparticles with near-infrared persistent luminescence and tunable sizes for tumor afterglow imaging and chemo-/photodynamic therapies. ACS Nano. 2018;12:4246-58.

55. Wang X, Zhuang J, Peng Q, Li YD. A general strategy for nanocrystal synthesis. Nature. 2005;437:121-4.

56. Li ZJ, Zhang YW, Wu X, Huang L, Li DS, Fan W, Han G. Direct aqueousphase synthesis of sub-10 nm "luminous pearls" with enhanced in vivo renewable near-infrared persistent luminescence. J Am Chem Soc. 2015;137:5304-7.

57. Li J-L, Shi J-P, Wang C-C, Li P-H, Yu Z-F, Zhang H-W. Five-nanometer ZnSn2O4:Cr, Eu ultra-small nanoparticles as new near infrared-emitting persistent luminescent nanoprobes for cellular and deep tissue imaging at $800 \mathrm{~nm}$. Nanoscale. 2017;9:8631-8.

58. Wang HF, Chen $X$, Feng F, Ji X, Zhang Y. EDTA etching: a simple way for regulating the traps, size and aqueous-dispersibility of $\mathrm{Cr}^{3+}$-doped zinc gallate. Chem Sci. 2018;9:8923-9.

59. Mout R, Moyano DF, Rana S, Rotello VM. Surface functionalization of nanoparticles for nanomedicine. Chem Soc Rev. 2012;41:2539-44.

60. Gu ZJ, Yan L, Tian G, Li SJ, Chai ZF, Zhao YL. Recent advances in design and fabrication of upconversion nanoparticles and their safe theranostic applications. Adv Mater. 2013;25:3758-79.

61. Medintz IL, Uyeda HT, Goldman ER, Mattoussi H. Quantum dot bioconjugates for imaging, labelling and sensing. Nat Mater. 2005;4:435-46.

62. Algar WR, Prasuhn DE, Stewart MH, Jennings TL, Blanco-Canosa JB, Dawson PE, Medintz IL. The controlled display of biomolecules on nanoparticles: a challenge suited to bioorthogonal chemistry. Bioconjug Chem. 2011;22:825-58.

63. Maldiney T, Richard C, Seguin J, Wattier N, Bessodes M, Scherman D. Effect of core diameter, surface coating, and peg chain length on the biodistribution of persistent luminescence nanoparticles in mice. ACS Nano. 2011;5:854-62.

64. Maldiney T, Bessiere A, Seguin J, Teston E, Sharma SK, Viana B, Bos AJ, Dorenbos P, Bessodes M, Gourier D, et al. The in vivo activation of persistent nanophosphors for optical imaging of vascularization, tumours and grafted cells. Nat Mater. 2014;13:418-26.

65. Song $L$, Lin XH, Song XR, Chen S, Chen XF, Li J, Yang HH. Repeatable deep-tissue activation of persistent luminescent nanoparticles by soft $X$-ray for high sensitivity long-term in vivo bioimaging. Nanoscale. 2017:9:2718-22.

66. Feng Y, Liu R, Zhang L, Li Z, Su Y, Lv Y. Raspberry-like mesoporous $\mathrm{Zn}_{1.07} \mathrm{Ga}_{2.34} \mathrm{Si}_{0.98} \mathrm{O}_{6.56}: \mathrm{Cr}_{0.01}$ nanocarriers for enhanced near-infrared afterglow imaging and combined cancer chemotherapy. ACS Appl Mater Interfaces. 2019;11:44978-88.

67. Wang Y, Yang CX, Yan XP. Hydrothermal and biomineralization synthesis of a dual-modal nanoprobe for targeted near-infrared persistent luminescence and magnetic resonance imaging. Nanoscale. 2017;9:9049-55
68. Li J, Shi J, Shen J, Man H, Wang M, Zhang H. Specific recognition of breast cancer cells in vitro using near infrared-emitting long-persistence luminescent $\mathrm{Zn}_{3} \mathrm{Ga}_{2} \mathrm{Ge}_{2} \mathrm{O}_{10}: \mathrm{Cr}^{3+}$ nanoprobes. Nano-micro Lett. 2015;7:138-45.

69. Chen HM, Sun XL, Wang GD, Nagata K, Hao ZL, Wang A, Li ZB, Xie J, Shen BZ. LiGa ${ }_{5} \mathrm{O}_{8}$ :Cr-based theranostic nanoparticles for imagingguided $X$-ray induced photodynamic therapy of deep-seated tumors. Mater Horiz. 2017;4:1092-101.

70. Liu JM, Zhang DD, Fang GZ, Wang S. Erythrocyte membrane bioinspired near-infrared persistent luminescence nanocarriers for in vivo longcirculating bioimaging and drug delivery. Biomaterials. 2018;165:39-47.

71. Li YJ, Yang CX, Yan XP. Biomimetic persistent luminescent nanoplatform for autofluorescence-free metastasis tracking and chemophotodynamic therapy. Anal Chem. 2018;90:4188-95.

72. Wang Z-H, Liu J-M, Zhao N, Li C-Y, Lv S, Hu Y, Lv H, Wang D, Wang S. Cancer cell macrophage membrane-camouflaged persistent-luminescent nanoparticles for imaging-guided photothermal therapy of colorectal cancer. ACS Appl Nano Mater. 2020;3:7105-18.

73. Wang ZH, Liu JM, Li CY, Wang D, Lv H, Lv SW, Zhao N, Ma H, Wang S. Bacterial biofilm bioinspired persistent luminescence nanoparticles with gut-oriented drug delivery for colorectal cancer imaging and chemotherapy. ACS Appl Mater Interfaces. 2019;11:36409-19.

74. Gnach A, Lipinski T, Bednarkiewicz A, Rybka J, Capobianco JA. Upconverting nanoparticles: assessing the toxicity. Chem Soc Rev. 2015:44:1561-84.

75. Sharifi S, Behzadi S, Laurent S, Forrest ML, Stroeve P, Mahmoudi M. Toxicity of nanomaterials. Chem Soc Rev. 2012;41:2323-43.

76. Hardman R. A toxicologic review of quantum dots: toxicity depends on physicochemical and environmental factors. Environ Health Perspect. 2006;1 14:165-72.

77. Khlebtsov N, Dykman L. Biodistribution and toxicity of engineered gold nanoparticles: a review of in vitro and in vivo studies. Chem Soc Rev. 2011:40:1647-71.

78. Sun X, Shi JP, Fu XY, Yang Y, Zhang HW. Long-term in vivo biodistribution and toxicity study of functionalized near-infrared persistent luminescence nanoparticles. Sci Rep. 2018;8:1-11.

79. Jiang Y, Li Y, Richard C, Scherman D, Liu YS. Hemocompatibility investigation and improvement of near-infrared persistent luminescent nanoparticle $\mathrm{ZnGa}_{2} \mathrm{O}_{4}: \mathrm{Cr}^{3+}$ by surface PEGylation. J Mater Chem B. 2019:7:3796-803.

80. Ramirez-Garcia G, Gutierrez-Granados S, Gallegos-Corona MA, PalmaTirado L, d'Orlye F, Varenne A, Mignet N, Richard C, Martinez-Alfaro M. Long-term toxicological effects of persistent luminescence nanoparticles after intravenous injection in mice. Int J Pharm. 2017;532:686-95.

81. Maldiney T, Remond M, Bessodes M, Scherman D, Richard C. Controlling aminosilane layer thickness to extend the plasma half-life of stealth persistent luminescence nanoparticles in vivo. J Mater Chem B. 2015;3:4009-16.

82. Weissleder R. A clearer vision for in vivo imaging. Nat Biotechnol. 2001;19:316-7.

83. Smith AM, Mancini MC, Nie SM. Second window for in vivo imaging Nat Nanotechnol. 2009;4:710-1.

84. Li JL, Shi JP, Wang CC, Li PH, Yu ZF, Zhang HW. Five-nanometer $\mathrm{ZnSn}_{2} \mathrm{O}_{4}$ : $\mathrm{Cr}$, Eu ultra-small nanoparticles as new near infrared-emitting persistent luminescent nanoprobes for cellular and deep tissue imaging at 800 nm. Nanoscale. 2017;9:8631-8.

85. Xue ZL, Li XL, Li YB, Jiang MY, Ren GZ, Liu HR, Zeng SJ, Hao JH. A 980 nm laser-activated upconverted persistent probe for NIR-to-NIR rechargeable in vivo bioimaging. Nanoscale. 2017;9:7276-83.

86. Zheng B, Bai Y, Chen H, Pan H, Ji W, Gong X, Wu X, Wang H, Chang J. Near-infrared light-excited upconverting persistent nanophosphors in vivo for imaging-guided cell therapy. ACS Appl Mater Interfaces. 2018;10:19514-22.

87. Qiu XC, Zhu XJ, Xu M, Yuan W, Feng W, Li FY. Hybrid Nanoclusters for near-infrared to near-infrared upconverted persistent luminescence bioimaging. ACS Appl Mater Interfaces. 2017;9:32583-90.

88. Chen X, Song J, Chen X, Yang H. X-ray-activated nanosystems for theranostic applications. Chem Soc Rev. 2019;48:3073-101.

89. Xue Z, Li X, Li Y, Jiang M, Liu H, Zeng S, Hao J. X-ray-activated nearinfrared persistent luminescent probe for deep-tissue and renewable in vivo bioimaging. ACS Appl Mater Interfaces. 2017;9:22132-42. 
90. Lin XH, Song L, Chen S, Chen XF, Wei JJ, Li J, Huang G, Yang HH. Kiwifruit-like persistent luminescent nanoparticles with high-performance and in situ activable near-infrared persistent luminescence for longterm in vivo bioimaging. ACS Appl Mater Interfaces. 2017;9:41181-7.

91. Zheng S, Shi J, Fu X, Wang C, Sun X, Chen C, Zhuang Y, Zou X, Li Y, Zhang $\mathrm{H}$. X-ray recharged long afterglow luminescent nanoparticles $\mathrm{MgGeO}_{3}: \mathrm{Mn}^{2+}, \mathrm{Y}^{\mathrm{b} 3}+{ }^{\mathrm{L}}{ }_{\mathrm{i}}+$ in the first and second biological windows for long-term bioimaging. Nanoscale. 2020;12:14037-46.

92. Chen ZZ, Wang LC, Manoharan D, Lee CL, Wu LC, Huang WT, Huang EY, Su CH, Sheu HS, Yeh CS. Low dose of X-Ray-excited long-lasting luminescent concave nanocubes in highly passive targeting deep-seated hepatic tumors. Adv Mater. 2019;31:1905087.

93. Sun X, Huang X, Guo J, Zhu W, Ding Y, Niu G, Wang A, Kiesewetter DO, Wang ZL, Sun S, Chen X. Self-illuminating ${ }^{64} \mathrm{Cu}$-doped CdSe/ ZnS nanocrystals for in vivo tumor imaging. J Am Chem Soc. 2014;136:1706-9.

94. Wu M, Shu J. Multimodal molecular imaging: current status and future directions. Contrast Media Mol Imaging. 2018;2018:1382183.

95. Liu H, Ren F, Zhang H, Han Y, Qin H, Zeng J, Wang Y, Sun Q, Li Z, Gao M. Oral administration of highly bright $\mathrm{Cr}^{3+}$ doped $\mathrm{ZnGa}_{2} \mathrm{O}_{4}$ nanocrystals for in vivo targeted imaging of orthotopic breast cancer. J Mater Chem B. 2018;6:1508-18.

96. Abdukayum A, Yang CX, Zhao Q, Chen JT, Dong LX, Yan XP. Gadolinium complexes functionalized persistent luminescent nanoparticles as a multimodal probe for near-infrared luminescence and magnetic resonance imaging in vivo. Anal Chem. 2014;86:4096-101.

97. Lu YC, Yang CX, Yan XP. Radiopaque tantalum oxide coated persistent luminescent nanoparticles as multimodal probes for in vivo near-infrared luminescence and computed tomography bioimaging. Nanoscale. 2015;7:17929-37.

98. Wu S, Li Y, Zhang R, Fan K, Ding W, Xu L, Zhang L. Persistent luminescence-polypyrrole nanocomposite for dual-modal imaging and photothermal therapy of mammary cancer. Talanta. 2021;221:121435

99. Liu JM, Liu YY, Zhang DD, Fang GZ, Wang S. Synthesis of $\mathrm{GdAlO}_{3}: \mathrm{Mn}^{4+}$, $\mathrm{G}^{\mathrm{e}}+\mathrm{Q} @$ Au core-shell nanoprobes with plasmon-enhanced near-infrared persistent luminescence for in vivo trimodality bioimaging. ACS Appl Mater Interfaces. 2016;8:29939-49.

100. Maldiney T, Doan B-T, Alloyeau D, Bessodes M, Scherman D, Richard C. Gadolinium-doped persistent nanophosphors as versatile tool for multimodal in vivo imaging. Adv Funct Mater. 2015;25:331-8.

101. Jinlei $L$, Jiaqing $G$, Hao $L$, Junle $Q$, Jun $S$. Simultaneous realization of persistent luminescence and $\mathrm{CT}$ dual-mode imaging by $\mathrm{x}$-ray recharged $\mathrm{Bi}_{2} \mathrm{Ga}_{4} \mathrm{O}_{9}$ : $\mathrm{Cr}$ nanoprobes in depth-independent tumors. Chem Eng J. 2021;406:126008.

102. Ai T, Shang W, Yan H, Zeng C, Wang K, Gao Y, Guan T, Fang C, Tian J. Near infrared-emitting persistent luminescent nanoparticles for Hepatocellular Carcinoma imaging and luminescence-guided surgery. Biomaterials. 2018;167:216-25.

103. Zou L, Wang H, He B, Zeng L, Tan T, Cao H, He X, Zhang Z, Guo S, Li Y. Current approaches of photothermal therapy in treating cancer metastasis with nanotherapeutics. Theranostics. 2016;6:762-72.

104. Zheng B, Chen HB, Zhao PQ, Pan HZ, Wu XL, Gong XQ, Wang HJ, Chang J. Persistent luminescent nanocarrier as an accurate tracker in vivo for near infrared-remote selectively triggered photothermal therapy. ACS Appl Mater Interfaces. 2016;8:21603-11.

105. Chen LJ, Sun SK, Wang Y, Yang CX, Wu SQ, Yan XP. Activatable multifunctional persistent luminescence nanoparticle/copper sulfide nanoprobe for in vivo luminescence imaging-guided photothermal therapy. ACS Appl Mater Interfaces. 2016;8:32667-74.

106. Lovell JF, Liu TWB, Chen J, Zheng G. Activatable photosensitizers for imaging and therapy. Chem Rev. 2010;110:2839-57.

107. Dolmans DEJGJ, Fukumura D, Jain RK. Photodynamic therapy for cancer. Nat Rev Cancer. 2003;3:380-7.

108. Fan W, Huang P, Chen X. Overcoming the Achilles' heel of photodynamic therapy. Chem Soc Rev. 2016;45:6488-519.

109. Wang J, Li Y, Mao R, Wang Y, Yan X, Liu J. Persistent luminescent nanoparticles as energy mediators for enhanced photodynamic therapy with fractionated irradiation. J Mater Chem B. 2017;5:5793-805.

110. Yang J, Zhao Y, Meng Y, Zhu H, Yan D, Liu C, Xu C, Zhang H, Xu L, Li $Y$, Liu Y. Irradiation-free photodynamic therapy in vivo induced by enhanced deep red afterglow within NIR-I bio-window. Chem Eng J. 2020;387:124067.

111. Liu G, Zhang S, Shi Y, Huang X, Tang Y, Chen P, Si W, Huang W, Dong $X$. "Wax-Sealed" theranostic nanoplatform for enhanced afterglow imaging-guided photothermally triggered photodynamic therapy. Adva Funct Mater. 2018;28:1804317.

112. Fan W, Lu N, Xu C, Liu Y, Lin J, Wang S, Shen Z, Yang Z, Qu J, Wang T, et al. Enhanced afterglow performance of persistent luminescence implants for efficient repeatable photodynamic therapy. ACS Nano. 2017;11:5864-72.

113. Sun SK, Wu JC, Wang H, Zhou L, Zhang C, Cheng R, Kan D, Zhang X, Yu C. Turning solid into gel for high-efficient persistent luminescencesensitized photodynamic therapy. Biomaterials. 2019;218:119328.

114. Abdurahman R, Yang C-X, Yan X-P. Conjugation of a photosensitizer to near infrared light renewable persistent luminescence nanoparticles for photodynamic therapy. Chem Commun. 2016;52:13303-6.

115. Hu L, Wang P, Zhao M, Liu L, Zhou L, Li B, Albaqami FH, El-Toni AM, Li $X, X i e Y$, et al. Near-infrared rechargeable "optical battery" implant for irradiation-free photodynamic therapy. Biomaterials. 2018;163:154-62.

116. Ma L, Zou X, Bui B, Chen W, Song KH, Solberg T. X-ray excited ZnS:Cu, Co afterglow nanoparticles for photodynamic activation. Appl Phys Lett. 2014;105:013702.

117. Chen H, Wang GD, Chuang YJ, Zhen Z, Chen X, Biddinger P, Hao Z, Liu F, Shen B, Pan Z, Xie J. Nanoscintillator-mediated X-ray inducible photodynamic therapy for in vivo cancer treatment. Nano Lett. 2015;15:2249-56.

118. Shi T, Sun W, Qin R, Li D, Feng Y, Chen L, Liu G, Chen X, Chen H. X-Rayinduced persistent luminescence promotes ultrasensitive imaging and effective inhibition of orthotopic hepatic tumors. Adv Funct Mater. 2020;30:2001166.

119. Song L, Li P-P, Yang W, Lin X-H, Liang H, Chen X-F, Liu G, Li J, Yang H-H. Low-dose $X$-ray activation of W(VI)-doped persistent luminescence nanoparticles for deep-tissue photodynamic therapy. Adv Funct Mater. 2018;28:1707496

120. Chan MH, Huang WT, Wang J, Liu RS, Hsiao M. Next-generation cancer-specific hybrid theranostic nanomaterials: MAGE-A3 NIR persistent luminescence nanoparticles conjugated to afatinib for in situ suppression of lung adenocarcinoma growth and metastasis. Adv Sci. 2020;7:1903741.

121. Zhang HJ, Zhao X, Chen L, Yang CX, Yan XP. pH-Driven Targeting nanoprobe with dual-responsive drug release for persistent luminescence imaging and chemotherapy of tumor. Anal Chem. 2020;92:1179-88.

122. Chen LJ, Yang CX, Yan XP. Liposome-coated persistent luminescence nanoparticles as luminescence trackable drug carrier for chemotherapy. Anal Chem. 2017;89:6936-9.

123. Feng $S$, Zhang $X$, Shi D, Wang Z. Zeolitic imidazolate framework-8 (ZIF-8) for drug delivery: a critical review. Front Chem Sci Eng. 2020;15:221-37.

124. Zhao H, Shu G, Zhu J, Fu Y, Gu Z, Yang D. Persistent luminescent metal-organic frameworks with long-lasting near infrared emission for tumor site activated imaging and drug delivery. Biomaterials. 2019;217:119332.

125. Lv Y, Ding D, Zhuang Y, Feng Y, Shi J, Zhang H, Zhou TL, Chen H, Xie RJ. Chromium-doped zinc gallogermanate@zeolitic imidazolate framework-8: a multifunctional nanoplatform for rechargeable in vivo persistent luminescence imaging and ph-responsive drug release. ACS Appl Mater Interfaces. 2019;11:1907-16.

126. Jiang W, Huang L, Mo F, Zhong Y, Xu L, Fu F. Persistent luminescent multifunctional drug delivery nano-platform based on nanomaterial $\mathrm{ZnGa}_{2} \mathrm{O}_{4}: \mathrm{Cr}^{3+}, \mathrm{S}^{\mathrm{n}}+$ for imaging-guided cancer chemotherapy. J Mater Chem B. 2019;7:3019-26.

127. Das SK, Menezes ME, Bhatia S, Wang XY, Emdad L, Sarkar D, Fisher PB. Gene Therapies for cancer: strategies, challenges and successes. J Cell Physiol. 2015:230:259-71.

128. Qin L, Yan P, Xie C, Huang J, Ren Z, Li X, Best S, Cai X, Han G. Gold nanorod-assembled $\mathrm{ZnGa}_{2} \mathrm{O}_{4}$ : $\mathrm{Cr}$ nanofibers for LED-amplified gene silencing in cancer cells. Nanoscale. 2018;10:13432-42.

129. Wu S-Q, Yang C-X, Yan X-P. A Dual-functional persistently luminescent nanocomposite enables engineering of mesenchymal stem cells for homing and gene therapy of glioblastoma. Adv Funct Mater. 2017;27:1604992. 
130. Wu S, Qiao Z, Li Y, Hu S, Ma Y, Wei S, Zhang L. Persistent luminescence nanoplatform with fenton-like catalytic activity for tumor multimodal imaging and photoenhanced combination therapy. ACS Appl Mater Interfaces. 2020;10:25572-80.

131. Wang Q, Liu N, Hou Z, Shi J, Su X, Sun X. Radioiodinated persistent luminescence nanoplatform for radiation-induced photodynamic therapy and radiotherapy. Adv Healthc Mater. 2020;10:2000802.

132. Zhao X, Zhao K, Chen L, Liu Y, Liu J, Yan X. A pH reversibly activatable NIR photothermal/photodynamic-in-one agent integrated with renewable nanoimplants for image-guided precision phototherapy. Chem Sci. 2021;12:442-52.

\section{Publisher's Note}

Springer Nature remains neutral with regard to jurisdictional claims in published maps and institutional affiliations.
Ready to submit your research? Choose BMC and benefit from:

- fast, convenient online submission

- thorough peer review by experienced researchers in your field

- rapid publication on acceptance

- support for research data, including large and complex data types

- gold Open Access which fosters wider collaboration and increased citations

- maximum visibility for your research: over $100 \mathrm{M}$ website views per year

At BMC, research is always in progress.

Learn more biomedcentral.com/submissions 